\title{
Development of a Taxonomy of Sociocultural Factors that Influence Decision Making
}

by Charneta Samms, Susan Hill, Asisat Animashaun, Shanell Henry, Debra Patton, and Diane Ungvarsky 


\section{Army Research Laboratory}

Aberdeen Proving Ground, MD 21005-5424

\section{Development of a Taxonomy of Sociocultural Factors that Influence Decision Making}

Charneta Samms, Susan Hill, Asisat Animashaun, Shanell Henry, Debra Patton, and Diane Ungvarsky Human Research and Engineering Directorate, ARL 


\section{REPORT DOCUMENTATION PAGE}

Form Approved OMB No. 0704-0188

Public reporting burden for this collection of information is estimated to average 1 hour per response, including the time for reviewing instructions, searching existing data sources, gathering and maintaining the data needed, and completing and reviewing the collection information. Send comments regarding this burden estimate or any other aspect of this collection of information, including suggestions for reducing the burden, to Department of Defense, Washington Headquarters Services, Directorate for Information Operations and Reports (0704-0188), 1215 Jefferson Davis Highway, Suite 1204, Arlington, VA 22202-4302. Respondents should be aware that notwithstanding any other provision of law, no person shall be subject to any penalty for failing to comply with a collection of information if it does not display a currently valid OMB control number.

PLEASE DO NOT RETURN YOUR FORM TO THE ABOVE ADDRESS.
1. REPORT DATE $(D D-M M-Y Y Y Y)$
2. REPORT TYPE
3. DATES COVERED (From - To)

February 2015

Final

4. TITLE AND SUBTITLE

Development of a Taxonomy of Sociocultural Factors that Influence Decision Making

$5 / 1 / 2012-1 / 13 / 2013$

5a. CONTRACT NUMBER

5b. GRANT NUMBER

5c. PROGRAM ELEMENT NUMBER

5d. PROJECT NUMBER

6UTHOR(S)

Charneta Samms, Susan Hill, Asisat Animashaun, Shanell Henry, Debra Patton and Diane Ungvarsky

US Army Research Laboratory

ATTN: RDRL-HRM-D

Aberdeen Proving Ground, MD 21005-5425

9. SPONSORING/MONITORING AGENCY NAME(S) AND ADDRESS(ES) 5e. TASK NUMBER

5f. WORK UNIT NUMBER

8. PERFORMING ORGANIZATION REPORT NUMBER

ARL-TR-7207

10. SPONSOR/MONITOR'S ACRONYM(S)

11. SPONSOR/MONITOR'S REPORT

NUMBER(S)

\section{DISTRIBUTION/AVAILABILITY STATEMENT}

Approved for public release; distribution is unlimited.

\section{SUPPLEMENTARY NOTES}

\section{ABSTRACT}

The US Army Research Laboratory’s (ARL's) Human Research and Engineering Directorate (HRED) launched a research program entitled Relevant Information for Social Cultural Depiction (RISC-D). The RISC-D program is concentrated on understanding and modeling the sociocultural factors that affect Soldier and Commander decision making, specially addressing how a Soldier's own cultural background influences their own decision making. This report discusses the development of a taxonomy of sociocultural factors that influence decision making to include the development process, the elements of the taxonomy, the proposed model and general framework.

\section{SUBJECT TERMS}

sociocultural, social cultural, taxonomy, decision making, culture

\begin{tabular}{|l|l|l|c|c|l|}
\hline \multicolumn{2}{|l|}{ 16. SECURITY CLASSIFICATION OF: } & $\begin{array}{c}\text { 17. LIMITATION } \\
\text { OF ABSTRACT }\end{array}$ & $\begin{array}{c}\text { 18. NUMBER } \\
\text { OF PAGES }\end{array}$ & $\begin{array}{l}\text { 19a. NAME OF RESPONSIBLE PERSON } \\
\text { Charneta Samms }\end{array}$ \\
\cline { 1 - 2 } $\begin{array}{l}\text { a. REPORT } \\
\text { Unclassified }\end{array}$ & $\begin{array}{l}\text { b. ABSTRACT } \\
\text { Unclassified }\end{array}$ & $\begin{array}{l}\text { c. THIS PAGE } \\
\text { Unclassified }\end{array}$ & UU & 64 & $\begin{array}{l}\text { 19b. TELEPHONE NUMBER (Include area code) } \\
410-278-5877\end{array}$ \\
\hline
\end{tabular}




\section{Contents}

List of Figures

List of Tables

1. Introduction $\quad 1$

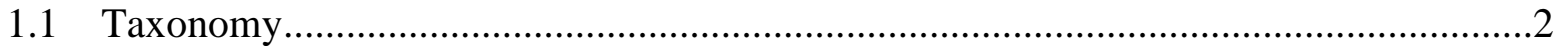

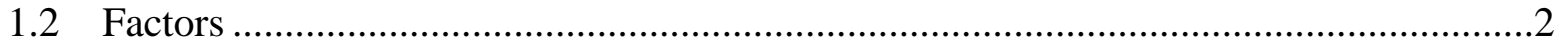

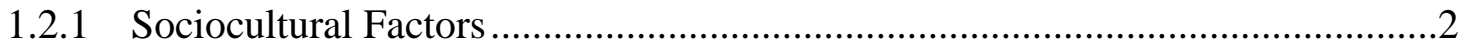

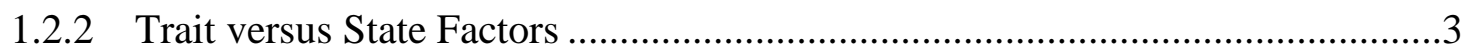

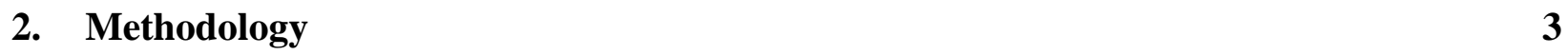

3. The Taxonomy: Categories and Definitions 4

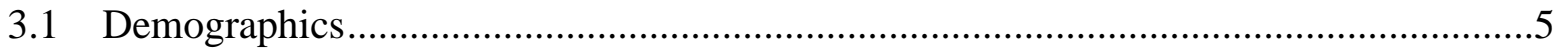

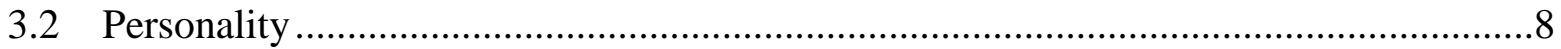

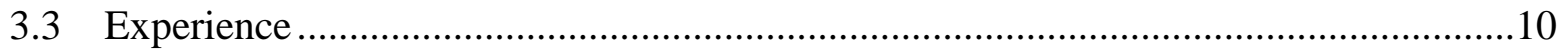

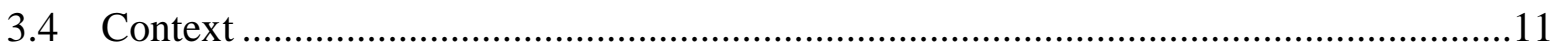

4. Reasoning and Impact of Social and Cultural Factors on Decision Making for the Taxonomy Elements $\quad 11$



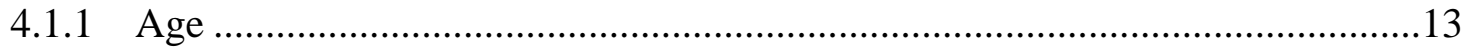

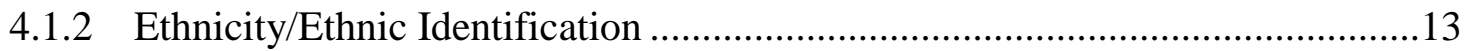

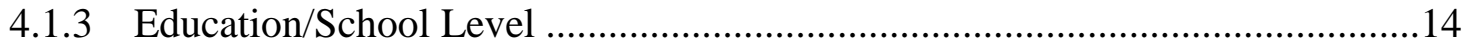

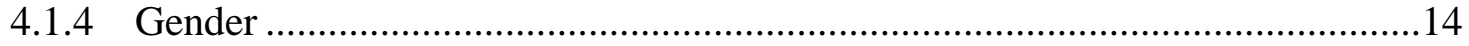

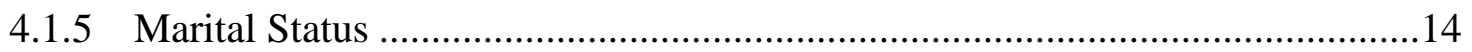

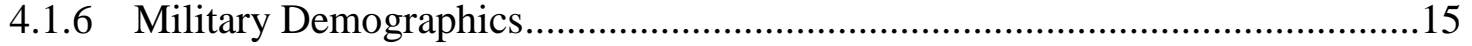

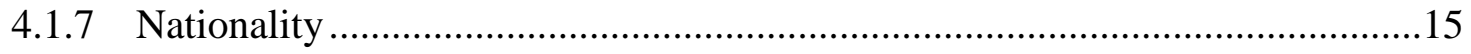

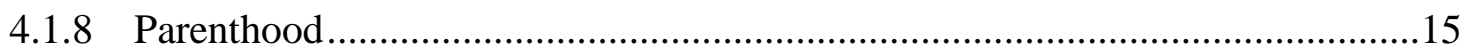

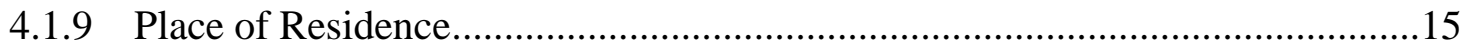



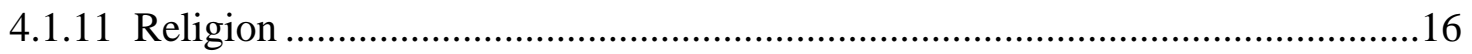

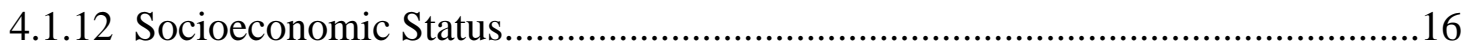

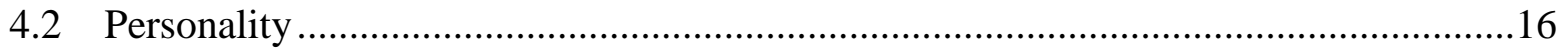




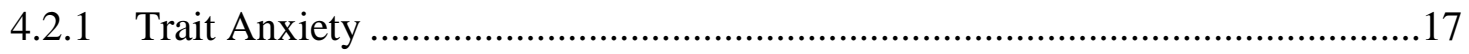

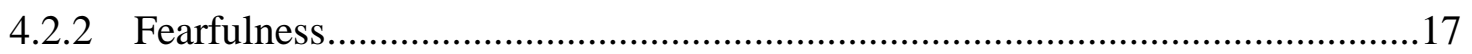

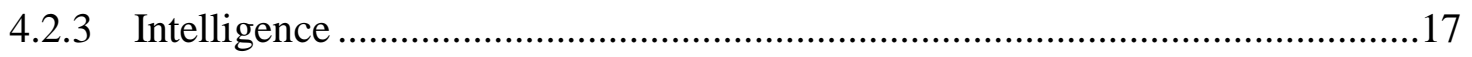

4.2.4 Cognitive Flexibility (Handling Uncertainty) ................................................18

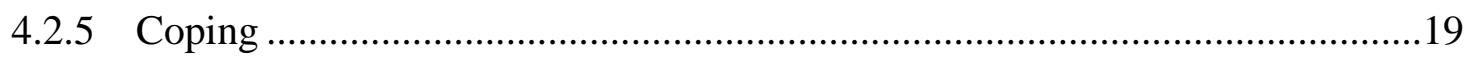

4.2.6 Self-Efficacy (Confidence)................................................................19

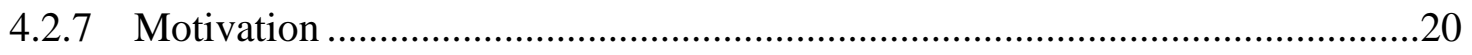

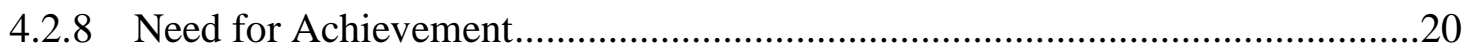

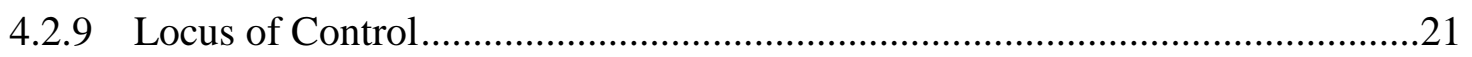

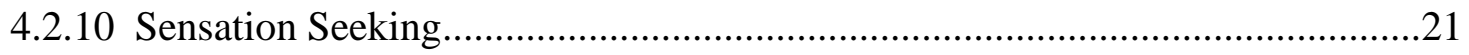

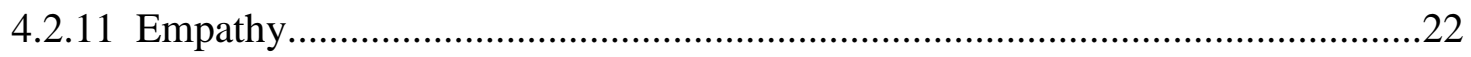

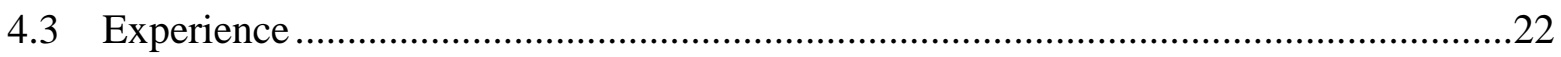

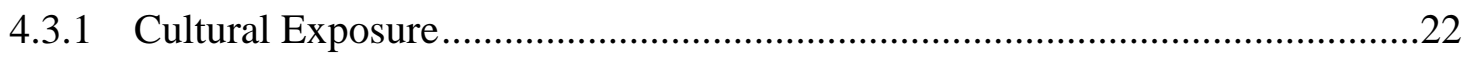

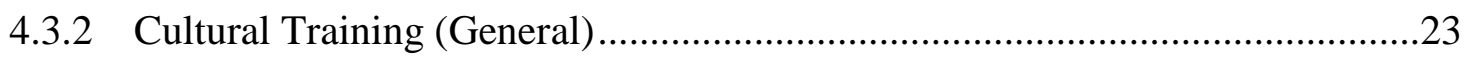

4.3.3 Cultural Training (Region-Specific) …………............................................24

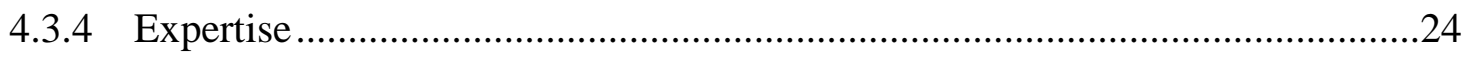

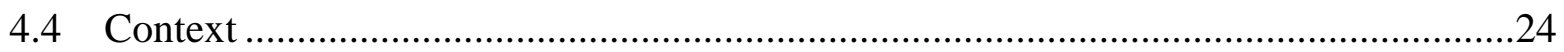

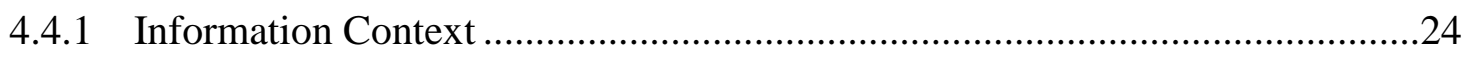

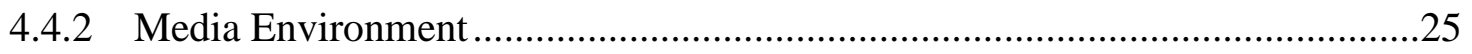

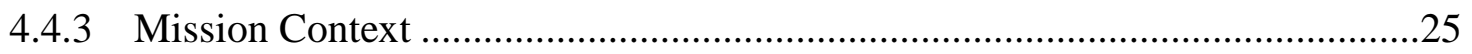

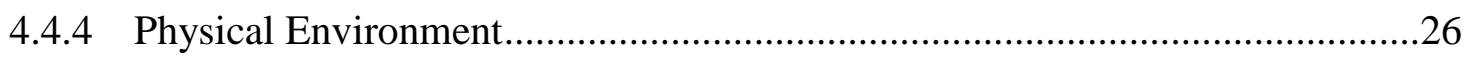

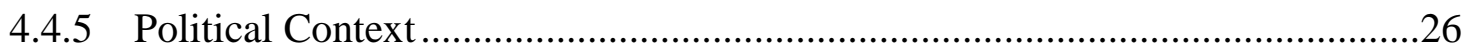

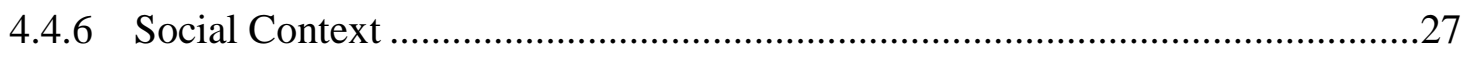

4.4.7 Temporal Context......................................................................................29

5. Proposed Model and General Framework $\quad 29$

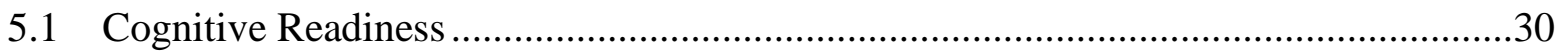

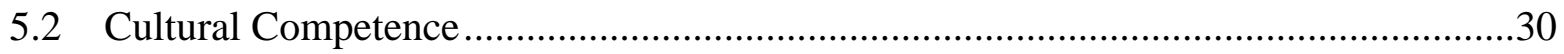

5.3 Fitness for Duty .....................................................................................................

6. Additional Items for Consideration 31

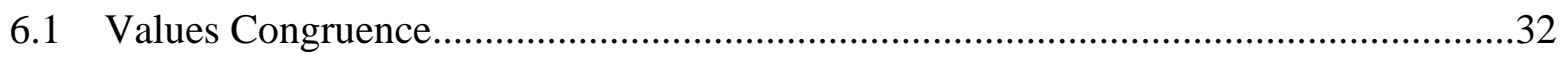

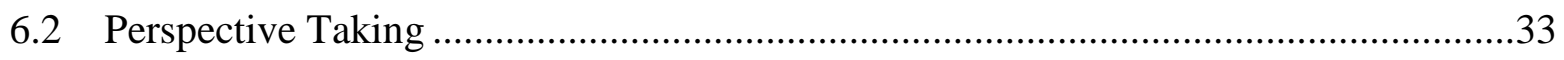

$\begin{array}{ll}\text { 7. Conclusions } & 34\end{array}$

$\begin{array}{llr}\text { 8. } & \text { References } & 35\end{array}$ 
List of Symbols, Abbreviations, and Acronyms

Distribution List 


\section{List of Figures}

Fig. 1 Adapted from Tannert's visual model of uncertainty (freely available [in public domain] from http://en.wikipedia.org/wiki/File:Uncertainty.svg).

Fig. 2 General framework of the influence of sociocultural factors on decision making.

\section{List of Tables}

Table 1 Final draft taxonomy of sociocultural factors that influence decision making-

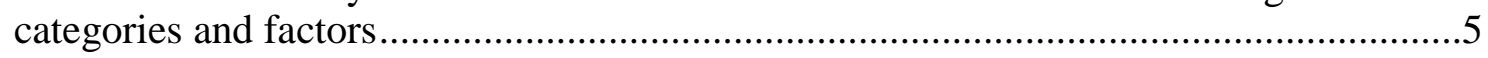

Table 2 Factors and definitions of demographics taxonomy element .....................................7

Table 3 Factors and definitions personality taxonomy element .............................................9

Table 4 Factors and definitions of the experience taxonomy element....................................10

Table 5 Factors and definitions of the context taxonomy element .........................................11

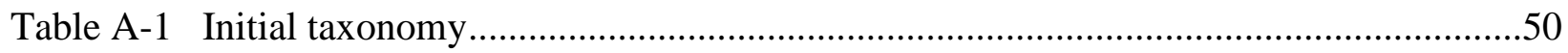


INTENTIONALLY LEFT BLANK. 


\section{Introduction}

Today's Soldiers and Commanders are facing a wider variety of missions in varying cultural environments. Expectations are that Soldiers and Commanders can enter into these new cultural environments with new mission types and achieve success enabled solely by the various types of training they receive. However, that easy transition is not always the case. Past missions demonstrate that training alone may not be enough to ensure mission success in these varying cultural landscapes. In a review of the past decade of combat, the Joint Staff J7 Joint and Coalition Operational Analysis (JCOA) Division identified that, "Because the traditional intelligence effort tended to focus on enemy groups and actions, it often neglected 'white' information about the population that was necessary for success in population-centric campaigns, such as counterinsurgency (COIN) operations. Local commanders needed information about ethnic and tribal identities, religion, culture, politics, and economics” (JCOA 2012). In addition to cultural training then, cultural information is just as vital to mission success in these diverse environments.

Understanding culture and its impact on mission achievement can be the difference between mission success and mission failure. To this end, a large amount of research is being conducted to understand the cultural environments in which Soldiers are sent to interact. Department of Defense (DOD) research programs, such as the Minerva Initiative, strive “...to build deeper understanding of the social, cultural, and political dynamics that shape regions of strategic interest around the world." (additional information can be found at: http://minerva.dtic.mil/). The Human Social, Culture and Behavior (HSCB) Modeling Program (additional information can be found at: http://www.dtic.mil/biosys/hscb-mp.html) is another example of a program focused on external sociocultural phenomena. This type of research leads to better understanding of the host population and the cultural environments in which Soldiers must perform.

In addition to understanding the host population, it is also important to understand cultures with which Soldiers must work. Among lessons learned in past operations, JCOA also noted "Lack of unity of effort between civilian and military organizations tended to be a key component of transition challenges" (JCOA 2012). One of these hindrances included a “...lack of understanding of counterpart cultures and bureaucratic processes” (JCOA 2012). In a Mission Command white paper, service culture was identified as important to instilling (institutionalizing) mission command and that "...the Joint Force derives strength from our distinct service cultures” (Joint Chiefs of Staff 2012). These points demonstrate a need for understanding the culture of our own military and civilian population.

Missions, such as humanitarian intervention, security, and defense support for civil authorities and stability operations, require Soldiers to make complex decisions in environments where the difference between non-combatants and combatants can be tough to discriminate. Unfortunately, 
decision-making research has not focused on the inclusion of culture (Guss 2004) and even less frequently on decision making in a military environment, including decision making on the effects of culture. Also, little research has been focused on the Soldier's and Commander's own sociocultural attributes and how that may affect their decision making. With this in mind, the US Army Research Laboratory's (ARL’s) Human Research and Engineering Directorate (HRED) has launched a research program entitled Relevant Information for Social Cultural Depiction (RISC-D). The RISC-D program is concentrated on understanding and modeling the sociocultural factors that affect Soldier and Commander decisions making, specially addressing how their own cultural background influences their own decision making. The first part of the RISC-D program was to develop a taxonomy of sociocultural factors that influence decision making. This report discusses that taxonomy and how it was developed.

\subsection{Taxonomy}

A taxonomy can be defined as a classification of key characteristics that focus on the general principles that describe a particular phenomena (Scherperell 2006). There are many examples of taxonomies that have been developed. In the business arena, Almotairi (2008) developed a taxonomy of success factors for customer relationship management (CRM). Through a review of the literature regarding CRM, Almotairi identified common factors most frequently identified as factors of success within CRM. Scherperell (2006) developed a taxonomy of decision orders that translated decision making into a classification triad of first, second, and third orders in relation to their primary field of usage and to the theoretical lens of the decision. This taxonomy served as the basis for the decision-order framework he developed to further the understanding of decision making. In the usability research arena, a context-of-use taxonomy was developed (Alonso-Rios et al. 2010). This taxonomy outlines context-of-use attributes that could be used as a formal model to support context-of-use studies and to ensure a common perspective. Similar to these taxonomies and others that have been identified (e.g., Carter et al. 2007; Tatham and Spens 2011), the taxonomy discussed in this report will serve as the base of research to develop a sociocultural influenced model of decision making.

\subsection{Factors}

A factor can be defined as an element contributing to a particular result or situation (http://dictionary.reference.com/browse/factor). In this report, factors make up the specific elements of the taxonomy. To better understand the taxonomy, definitions of sociocultural factors and state and trait factors are provided. Each factor in the taxonomy is of a sociocultural nature and can be classified as either a state factor and/or a trait factor.

\subsubsection{Sociocultural Factors}

Sociocultural is defined as "of, relating to or involving a combination of social and cultural factors” (from http://www.merriam-webster.com/medical/sociocultural). Sociocultural factors in terms of this taxonomy are defined as measurable elements descriptive of the social and cultural 
nature of the person and their environment. The social and cultural characteristics represents factors related to communal living, with the social aspect reflecting more of the individual and the cultural aspect reflecting more of the influence of the group on the individual.

\subsubsection{Trait versus State Factors}

A state is described as a condition or mode of being with regard to given circumstances (http://www.thefreedictionary.com/state). A trait can be defined as a distinguishing feature of a person's character (http://www.thefreedictionary.com/trait). The significance of these definitions in relation to this taxonomy is that the factors of interest are mostly trait factors to support the understanding of the individual decision maker. The state factors also support understanding but are specific to a given contextual environment.

This report discusses the taxonomy development process, introduces the taxonomy framework, and lays out the next steps for this line of research.

\section{Methodology}

The taxonomy development consisted of 3 processes: synthetic analysis, group brainstorming sessions, and a focused literature search. The concepts used for the taxonomy development process were derived from Whittaker and Breininger (2008) and DeRue and Morgeson (2005).

The first part of the taxonomy development started with a synthetic analysis. A synthetic analysis is defined as “...the process of conducting an extensive literature review to gain a synoptic view of a complex problem as a whole and detect links, commonalities and gaps in a given research area” (Samms et al. 2012). Research areas, such as decision making, culture, and military operations, were reviewed. Although an extensive amount of research was conducted in the area of decision making, most of that research is conducted in environments where the results may not necessarily directly apply to a military context. However, expanding the search beyond a military context to identify important sociocultural factors impacting decision making was seen as a necessary step. This realization led the researchers to expand the analysis into fields that could help identify sociocultural factors that link to decision making. Domains, such as business, management, economics, healthcare, scientific jury selection, and many others, were identified and thus expanded the search to select factors of interest for initial taxonomy development that may not be directly applicable but would be a good start for the taxonomy.

Using the knowledge generated by the synthetic analysis, a group brainstorming session was held. Researchers used sticky notes to record every sociocultural factor or idea that they thought could be related to decision making based on the expertise that was developed from the synthetic analysis and on other research literature the researchers had identified. After all thoughts were exhausted, the sticky notes were reviewed by the group. As the group reviewed each concept, 
discussion ensued as to whether the identified factor was a potentially influential construct to decision making. As discussion continued, researchers argued for or against constructs using supporting literature they had identified. Also during this discussion, duplicate concepts were combined and similar concepts were grouped together. Constructs that seemed dissimilar to the current groupings but were considered influential to decision making were put aside for further deliberation. Through this process, 6 major areas were identified that grouped approximately 50 factors. These 6 major areas were demographics, personality, experience, values, context, and external factors. The grouping of external factors emerged from items that were set aside from the discussion as related but not clearly connected to the main areas. This very early draft of the taxonomy can be found in the Appendix. These major areas served as the basis for the next round of literature review. Each researcher selected an area and used that to focus their continued literature search. While the synthetic analysis was a very broad stroke review, the focus of this round of literature review was to identify any current research that linked each specific, identified sociocultural factor within an area to decision making. Each researcher also needed to define each factor and provide the research rationale for including it into the taxonomy. This approach provided the opportunity to first look broadly for relevant information, reach a consensus on initial factors, and then conduct a focused literature review on how sociocultural factors impact decision making.

After this phase of the literature review was completed, the researchers reconvened to discuss findings and to develop the draft of the taxonomy that is presented in this report. During this discussion, much care was taken to ensure factors were indeed sociocultural in nature and quantifiable or describable. Ensuring each factor is quantifiable is crucial to the validation of the taxonomy in future research. With these restrictions and additional literature found, the groupings were changed to 4 major areas: demographics, personality, experience, and context. Section 3 of this report defines the current draft of the taxonomy, the 4 taxonomic categories, and their individual factors. Section 4 discusses the research behind why each factor was included.

\section{The Taxonomy: Categories and Definitions}

The taxonomy is divided into 4 main categories of sociocultural factors believed to be influential to decision making. Table 1 outlines the current taxonomy. 
Table 1 Final draft taxonomy of sociocultural factors that influence decision making—categories and factors

\begin{tabular}{|c|c|c|c|}
\hline Demographics & Personality & Experience & Context \\
\hline Age & Trait anxiety & Cultural exposure & Information context \\
\hline $\begin{array}{c}\text { Ethnicity/ethnic } \\
\text { identification }\end{array}$ & Fearfulness & Cultural training (general) & Media environment \\
\hline Education/school level & Intelligence & $\begin{array}{c}\text { Cultural training } \\
\text { (region-specific) }\end{array}$ & Mission context \\
\hline Gender & $\begin{array}{c}\text { Cognitive flexibility } \\
\text { (uncertainty) }\end{array}$ & Expertise & Physical environment \\
\hline Marital status & Coping & $\ldots$ & Political context \\
\hline Military demographics & Self-efficacy (Confidence) & $\ldots$ & Social context \\
\hline Nationality & Motivation & $\ldots$ & $\ldots$ \\
\hline Parenthood & Need for achievement & $\ldots$ & $\ldots$ \\
\hline Place of residence & Locus of control & $\ldots$ & $\ldots$ \\
\hline Race & Sensation-seeking & $\ldots$ & $\ldots$ \\
\hline Religion & Empathy & $\ldots$ & $\ldots$ \\
\hline
\end{tabular}

The remainder of this section will define each category and provide definitions for each factor.

\subsection{Demographics}

Demographic factors are often considered in research. Demographics refer to personal characteristics that are often examined statistically within populations, such as gender, age, religion, or marital status. Jehn et al. (1997) suggest that demographic factors can be characterized by 2 dimensions: visibility and informational. Visible factors refer to things you can see, such as age, gender, and race. Informational factors include things related to education and work experience, things that are not seen but can have other impacts. Visible factors, because they can be seen by all and cannot be hidden, can affect other people's perceptions and behaviors. However, informational factors can also affect other people's perceptions and behaviors; the difference is that informational factors may take time and effort to learn about, explore, and understand. In the development and use of this taxonomy, it may be important to 
consider if it is useful to think about demographics factors in terms of visible and informational and if those distinctions could have differential impacts on decision making.

Some demographic factors are relatively easy to collect and to analyze, such as marital status. They are factual information. For the most part, demographic data can be gained from direct questions. However, some demographic factors can be more complex and ambiguous. For example, factors of race, nationality, and ethnic identities can be very difficult to define. They may even be difficult to gather. Single check boxes for race (i.e., white, black, other) will not be adequate for truly capturing the complexity of mixed race and racial identification (e.g., Herring 1995; Payson 1996). National and ethnic identity, in environments where there are multiple identifications, can be very difficult.

Nevertheless, demographic factors are often categorized into discrete categories. Because they are often considered as statistical data, demographic factors are often used in statistical analysis, such as their use as a control variable.

Table 2 lists all of the demographic factors and their definitions. 
Table 2 Factors and definitions of demographics taxonomy element

\begin{tabular}{|c|c|}
\hline Factor & Description/Definition \\
\hline Age & $\begin{array}{l}\text { The length of an existence extending from the beginning to any given time } \\
\text { (http://www.merriam-webster.com/dictionary/age); how many years old an individual is }\end{array}$ \\
\hline $\begin{array}{l}\text { Ethnic } \\
\text { Identif }\end{array}$ & $\begin{array}{l}\text { Ethnic quality or affiliation-relating to large groups of people classed according to common } \\
\text { racial, national, tribal, religious, linguistic, or cultural origin or background } \\
\text { (http://www.merriam-webster.com/dictionary/ethnicity) }\end{array}$ \\
\hline $\begin{array}{l}\text { Educat } \\
\text { School }\end{array}$ & $\begin{array}{l}\text { The knowledge and development resulting from a learning process. Can be in a formalized } \\
\text { setting, such as a school; position or grade within a school that has been achieved (adapted from } \\
\text { http://www.merriam-webster.com/dictionary/education) }\end{array}$ \\
\hline Gender & $\begin{array}{l}\text { The behavioral, cultural, or psychological traits typically associated with one sex (i.e., male or } \\
\text { female) (http://www.merriam-webster.com/dictionary/gender) }\end{array}$ \\
\hline Marit & $\begin{array}{l}\text { The condition of being married or unmarried } \\
\text { (http://www.thefreedictionary.com/marital+status); can include other types of married or } \\
\text { unmarried states (e.g., divorced, separated, widowed) }\end{array}$ \\
\hline $\begin{array}{l}\text { Military } \\
\text { demographics } \\
\text { - Military status } \\
\text { subgroups } \\
\text { - Military } \\
\text { training/ } \\
\text { schooling } \\
\text { - Occupational } \\
\text { Specialty } \\
\text { - Rank } \\
\text { - Role } \\
\text { - Tenure }\end{array}$ & $\begin{array}{l}\text { Military population data (adapted from thefreedictionary.com) } \\
\text { - Military status subgroups (active duty vs. reserve) - active duty are full time members of the } \\
\text { armed services (http://www.thefreedictionary.com/active+duty and } \\
\text { http://www.thefreedictionary.com/reserves). Reserve components of the United States armed } \\
\text { forces are military organizations whose members, generally perform a minimum of } 39 \text { days of } \\
\text { military duty per year and who augment the active duty (or full time) military when necessary. } \\
\text { The reserve components are also referred to collectively as the Guard and Reserves } \\
\text { (http://en.wikipedia.org/wiki/Reserve_components_of_the_United_States_Armed_Forces) } \\
\text { - Military training - the instruction of personnel to enhance their capacity to perform specific } \\
\text { military functions and tasks (http://www.thefreedictionary.com/military+training) education } \\
\text { and training within the military; l } \\
\text { - Military Occupational Specialty (MOS) is the duty or related group of duties that a Soldier by } \\
\text { training, skill, and experience is best qualified to perform and that is a basis for the } \\
\text { classification, assignment, and advancement of enlisted personnel (http://www.merriam- } \\
\text { webster.com/dictionary/mos) } \\
\text { - Rank - relative status in a military organization } \\
\text { (http://www.thefreedictionary.com/military+training); military rating or paygrade; level } \\
\text { within the military hierarchy; officer or enlisted levels; system of hierarchical relationships in } \\
\text { armed forces } \\
\text { - Role - a function or part performed especially in a particular operation or process, within the } \\
\text { military work (http://www.merriam-webster.com/dictionary/role) } \\
\text { - Tenure in military (time in service)—the status of holding one’s position } \\
\text { (http://www.thefreedictionary.com/tenure); amount of time (years/months) spent in active } \\
\text { duty or reserve units }\end{array}$ \\
\hline Natio & $\begin{array}{l}\text { National status; specifically: a legal relationship involving allegiance on the part of an } \\
\text { individual and usually protection on the part of the state; a people having a common origin, } \\
\text { tradition, and language and capable of forming or actually constituting a nation-state } \\
\text { (http://www.merriam-webster.com/dictionary/nationality) }\end{array}$ \\
\hline Parent & $\begin{array}{l}\text { The state of being a parent (http://www.merriam-webster.com/dictionary/parenthood); an } \\
\text { individual is a parent or acts as a parent; to rear and nurture a child; be a father or mother }\end{array}$ \\
\hline $\begin{array}{l}\text { Place of } \\
\text { Residence }\end{array}$ & $\begin{array}{l}\text { place where one lives (http://www.merriam-webster.com/dictionary/residence) and how it } \\
\text { aracterized }\end{array}$ \\
\hline
\end{tabular}


Table 2 Factors and definitions of demographics taxonomy element (continued)

\begin{tabular}{|l|l|}
\hline \multicolumn{1}{|c|}{ Factor } & \multicolumn{1}{c|}{ Description/Definition } \\
\hline Race & $\begin{array}{l}\text { The term for a large body of persons who may be thought of as a unit because of } \\
\text { common characteristics. In the traditional biological and anthropological systems of } \\
\text { classification, race refers to a group of persons who share such genetically transmitted } \\
\text { traits as skin color, hair texture, and eye shape or color: the white race; the yellow race. } \\
\text { In reference to classifying the human species, race is now under dispute among modern } \\
\text { biologists and anthropologists. Some feel that the term has no biological validity } \\
\text { (http://dictionary.reference.com/browse/race?s=t) }\end{array}$ \\
\hline Religion & $\begin{array}{l}\text { The outward and often social articulation of belief in higher powers, often practiced in a } \\
\text { community setting; may include attendance of public worship and participation in the } \\
\text { rituals particular to the faith tradition being embraced } \\
\text { (http://dictionary.reference.com/browse/religion?s=t); a cause, principle, or system of } \\
\text { beliefs held to with ardor and faith (http://www.merriam- } \\
\text { webster.com/dictionary/religion) }\end{array}$ \\
\hline Socioeconomic status & $\begin{array}{l}\text { An individual's or group's position within a hierarchical social structure; depends on a } \\
\text { combination of variables, including occupation, education, income, wealth, and place of } \\
\text { residence (http://dictionary.reference.com/browse/socioeconomic\%20status?s=t) }\end{array}$ \\
\hline
\end{tabular}

\subsection{Personality}

According to Warren and Carmichael (1930), “. . . personality is the entire mental organization of a human being at any stage of his development.” More recently, Mayer (2005) describes personality as, “An individual's pattern of psychological processes arising from motives, feelings, thoughts, and other major areas of psychological function. Personality is expressed through its influences on the body, in conscious mental life, and through the individual's social behavior." To keep it simple, this taxonomy will define personality as a complex set of traits that distinguish an individual's behavioral and emotional characteristics.

Research demonstrates that the big 5 personality constructs (openness, conscientiousness, extraversion, agreeableness, and neuroticism) strongly predict work behavior across time, contexts, and cultures_-in domestic settings and in overseas assignments (Ang et al. 2006). Ang et al. (2006) also report that individual differences in traits (anxiety, cognitive adaptability, selfconfidence, etc.) “. . . serve as predictors of proximal state-like individual differences”, and they are predictive of international assignments. American Soldiers perform international fullspectrum operations and therefore it is important that their individual traits should be understood and taken into consideration when assigned overseas.

Table 3 lists all of the personality factors and their definitions. 
Table 3 Factors and definitions personality taxonomy element

\begin{tabular}{|c|c|}
\hline Factors & Description/Definition \\
\hline Trait anxiety & $\begin{array}{l}\text { Reflects the existence of stable individual differences in the tendency to respond with state } \\
\text { anxiety in the anticipation of threatening situations; closely related to the personality trait } \\
\text { of neuroticism; may be conscious or unconscious } \\
\text { (Schwarzer 1997) }\end{array}$ \\
\hline Fearfulness & $\begin{array}{l}\text { An unpleasant, often strong emotion caused by anticipation or awareness of danger and } \\
\text { accompanied by increased autonomic activity; induces high levels of anxiety } \\
\text { (http://www.merriam-webster.com/dictionary/fearfulness) }\end{array}$ \\
\hline Intelligence & $\begin{array}{l}\text { General mental ability involved in calculating, reasoning, perceiving relationships and } \\
\text { analogies, learning quickly, storing and retrieving information, using language fluently, } \\
\text { classifying, generalizing, and adjusting to new situations } \\
\text { (http://www.thefreedictionary.com/intelligence) }\end{array}$ \\
\hline $\begin{array}{l}\text { Uncertainty } \\
\text { (Cognitive } \\
\text { Flexibility) }\end{array}$ & $\begin{array}{l}\text { A state of having limited knowledge where it is impossible to exactly describe existing } \\
\text { state or future outcome, more than one possible outcome; entails a period of time } \\
\text { anticipation prior to confrontation with a potentially harmful event (Bar-Tal 1994; Greco } \\
\text { and Roger 2003) }\end{array}$ \\
\hline Coping style & $\begin{array}{l}\text { A person's characteristic strategies used in response to life problems or traumas; include } \\
\text { problem-focused thoughts or behaviors, seeking social support, wishful thinking, blaming } \\
\text { self, and avoidance (Vitaliano et al.1987) }\end{array}$ \\
\hline Self-efficacy & $\begin{array}{l}\text { The belief that people have in their ability to exercise control over events that affect their } \\
\text { lives (Bandura 1977) }\end{array}$ \\
\hline $\begin{array}{l}\text { Motivation } \\
\text { (intrinsic/extrinsic) }\end{array}$ & $\begin{array}{l}\text { Intrinsic: the doing of an activity for its inherent satisfaction rather than for some separable } \\
\text { consequence } \\
\text { Extrinsic: the doing of an activity simply for the enjoyment of the activity itself, rather } \\
\text { than its instrumental value; external motivations involve rewards that are produced outside } \\
\text { the organism (e.g., coming from social partners) (Oudeyer and Kaplan 2008) }\end{array}$ \\
\hline $\begin{array}{l}\text { Need for } \\
\text { achievement }\end{array}$ & $\begin{array}{l}\text { An enduring and consistent concern with setting and meeting high standards of } \\
\text { achievement influenced by internal and extrinsic motivation; motivates an individual to } \\
\text { succeed in competition, and to excel in activities important to him or her } \\
\text { (http://www.businessdictionary.com/definition/need-for-achievement.html) }\end{array}$ \\
\hline Locus of control & $\begin{array}{l}\text { Generalized expectancies for internal versus external control of reinforcement. } \\
\text { Internal: believe that their own actions determine the rewards that they obtain } \\
\text { External: believe that their own behavior doesn't matter much and that rewards in life are } \\
\text { generally outside of their control (Rotter 1966) }\end{array}$ \\
\hline Sensation-seeking & $\begin{array}{l}\text { An individual's desire for varied, complex, novel and intense stimulation (Zuckerman } \\
\text { 1971); includes risk perception and risk attitude }\end{array}$ \\
\hline Empathy & $\begin{array}{l}\text { The faculty to understand and act in response to unique affective experiences of another } \\
\text { person. It has } 3 \text { components: 1) an emotional response to another person; 2) a cognitive } \\
\text { faculty to take the perspective of the other person; and 3) some monitoring ability to keep } \\
\text { track of the origins (self vs. other) of the experienced feelings (Lamm et al. 2007); the } \\
\text { strategies used in understanding the thought, feelings, inner mental states, and motivations } \\
\text { of other people and the ability to recognize that others may have points of view different } \\
\text { from one's own }\end{array}$ \\
\hline
\end{tabular}




\subsection{Experience}

In his influential work, Thoughts on Art and Life, Leonardo DaVinci advises to "avoid the precepts of those thinkers whose reasoning is not confirmed by experience" (DaVinci 1906). Experience is the apprehension of an object, thought, or emotion through the senses or mind, either through direct observation of or participation in events. Experience coupled with relevance informs the basis of knowledge. There are 2 approaches to knowledge acquisition: by structured, regimented programs or by freeform, unstructured natural acquisition. All knowledge significantly impacts sociocultural intelligence, thereby influencing perception and decision making. Both of the aforementioned methods of knowledge acquisition will be explored in Section 4 to expound the effect of cultural experiences on decision making.

The military currently provides numerous types of training to increase Warfighter cultural intelligence, ranging from basic training, which instills the Warfighter ethos, to the progressive levels of the professional military education (PME), which prepares military officers for leadership. The US Army Training and Doctrine Command (TRADOC) Culture Center (TCC) educates and trains Soldiers preparing for deployment in the culture of the mission area and by providing tools to facilitate cultural learning. There are also language training centers that provide military transition teams (MiTTs) and other personnel with language training support. The US Army Research Institute (ARI) has developed programs and tools that increase crosscultural competency through simulation exercises, gesture interpretation training, and computerbased learning. Programs developed by the Human Resources Research Organization (HumRRO) and the North Carolina Center for World Languages \& Cultures (NCCWLC) have provided US forces with a plethora of information about specific customs and behaviors that are part of national cultures around the world (NCCWLC 1996, Hannaman 1997) and have been vital in the training of coalition allies and joint operations, further enabling cross-cultural communication.

Table 4 lists all of the experience factors and their definitions.

Table 4 Factors and definitions of the experience taxonomy element

\begin{tabular}{|l|l|}
\hline \multicolumn{1}{|c|}{ Factor } & \multicolumn{1}{c|}{ Description/Definition } \\
\hline Cultural Exposure & $\begin{array}{l}\text { Experiences related to a region that aid in developing a familiarity with or } \\
\text { understanding of the norms, values, and beliefs of that region (Crowne 2008) }\end{array}$ \\
\hline $\begin{array}{l}\text { Cultural Training } \\
\text { (general) }\end{array}$ & $\begin{array}{l}\text { Teaches about a culture by identifying the points on which cultures vary by providing } \\
\text { a framework to consider cultural similarities and differences (Abbe and Halpin 2010) }\end{array}$ \\
\hline $\begin{array}{l}\text { Cultural Training } \\
\text { (region-specific) }\end{array}$ & $\begin{array}{l}\text { Training that provides descriptive facts and figures about a locale, conveying } \\
\text { information of immediate relevance (Abbe and Halpin 2010) }\end{array}$ \\
\hline Expertise & Specialization in a particular concept, skill, or knowledge \\
\hline
\end{tabular}




\subsection{Context}

The word context has many meanings. However, in reference to this taxonomy, context is defined as ". . . the set of circumstances or facts that surround a particular event, situation, etc." (http://www.merriam-webster.com/dictionary/context). Context provides the background that will influence Soldier and Commander decision making. It can be described through the following factors: information context, media environment, mission context, physical environment, social context, and temporal context. Each factor will be discussed in detail in Section 4.

Table 5 lists all of the context factors and their definitions.

Table 5 Factors and definitions of the context taxonomy element

\begin{tabular}{|l|l|}
\hline \multicolumn{1}{|c|}{ Factor } & \multicolumn{1}{c|}{ Description/Definition } \\
\hline Information context & The quantity and quality of information available for use in decision making. \\
\hline Media environment & The extent to which the media has access to results of decision making. \\
\hline Mission context & The type of mission being conducted; humanitarian, counterinsurgency, etc. \\
\hline Physical environment & The external surroundings and conditions in which something exists. \\
\hline Political context & The political landscape of the environment where decisions need to be made. \\
\hline Social context & The social climate of the environment where decisions need to be made. \\
\hline Temporal context & $\begin{array}{l}\text { The time available to make decisions and number of decisions that need to be } \\
\text { made. }\end{array}$ \\
\hline
\end{tabular}

\section{Reasoning and Impact of Social and Cultural Factors on Decision Making for the Taxonomy Elements}

This section discusses each of the factors and the literature that supports its inclusion in the taxonomy. There are a number of studies that address the effect of various factors on decision making. The studies are drawn from a number of different application areas including healthcare, management, government, and politics. The purpose of this review is to identify factors that have been found in some way to affect decision making whether the scientific evidence was extensive or minimal.

Many of the studies (specifically within the demographic and personality elements) discuss multiple factors within 1 study. Therefore, some studies using multiple factors are briefly described with results sometimes repeated in another related section.

For example, 1 area where decision making has been examined extensively is in the healthcare environment. In particular, several studies identified factors affecting the decision making of patients about medical treatments. Levinson et al. (2005) looked at how demographic variables 
and health affected patient preferences for participating in clinical treatment decisions. The results showed that, "Women, more educated, and healthier people were more likely to prefer an active role in decision making. African-American and Hispanic respondents were more likely to prefer that physicians make the decisions”. Age also affected the preference for an active role in decision making, with preference increasing with individuals up to 45 years and then decreasing. These results show that the demographic factors of gender, education, race, ethnicity, and age can influence decision making, at least in this health care application.

Another study that addresses several demographic factors in the health care area shows the effect of various kinds of media information on decision making for health care. The study found that education level, gender, and place of residence influenced communication and decision making. Interestingly, patient age was not correlated (Passalacqua 2004).

Jackson et al. (1995) writes about the impact of diversity in decision-making teams and addresses several demographic factors. They discuss age diversity, gender diversity, and domestic cultural diversity (identified as those from non-“majority” population, such as AfricanAmericans and Hispanic-Americans). The authors developed a framework for examining the impact of diversity in decision-making teams, which includes considering the individual level, interpersonal level, and team level of task-related and social relations level factors within organizational and societal contexts. Within this framework, demographic factors are explicitly called out and are considered as part of the "input" for the team diversity framework. Interestingly, the context is an important consideration in the diversity and decision-making framework, just as context (discussed in Section 4.4) is one of the important factors that is included in our taxonomy.

Another area that is not specifically addressed within the taxonomy is the effect of visible or informational demographic factors on another's decision making. There were a number of studies that show how people perceived others' demographics, particularly with visible or observable factors, and how that perception influences decision making. For example, physical appearance (e.g., gender, age) affected decision making. Stereotypes of ethnic groups, as indicated by names, influenced decision making and acted as judgmental heuristics (Bodenhausen and Wyer 1985). Race influenced decision making (e.g., Shulman et al. 1999; Leiber and Jamieson 1995). Non-observable, informational demographics also affect decision making, such as the marital status of women affecting the physician-patient interactions for treatment of breast cancer (e.g., Silliman et al. 1997) or the socioeconomic status of a patient affecting doctor-patient communication (e.g., Wilems et al. 2005). For the purposes of this taxonomy, the researchers are looking at the elements as characteristics of the decision maker and how they affect his/her own decisions. But the researchers are also mindful of the effect of others' demographic characteristics on an individual's decision making.

Finally, one thing to keep in mind in this literature review is that much of the research has been performed in the US, or at least published in English language research journals. Therefore, it is 
possible that there is a cultural bias in the research, that is, the findings may not be generalized across all cultures. Of course, that is one of the purposes of looking at different ethnic, racial, and national groups. However, for some of the findings, such as for age or marital status, there may be cultural differences that are not fully reflected in the findings reported.

\subsection{Demographics}

In the following sections, each specific factor within the demographics category of the taxonomy is addressed. The section identifies research on how the factors affects decision making.

\subsubsection{Age}

Age would be considered a visible demographic variable because, for the most part, a person can guess the relative ages of individuals by visible cues. A number of studies have shown that age is related to decision making. Levinson et al. (2005) found that individuals up to 45 years old preferred active roles in health care decision making and after 45 years old, they showed a decreasing preference for active roles.

Martin et al. (2005) found age related to decision making, particularly to different decisionmaking styles. The authors surveyed the literature to determine if there were individual factors that were associated with different kinds of decision-making style. They found both age and gender related to decision-making style, although more literature is available on the connection of age and styles. Several researchers (e.g., Chen and Sun 2003; Kim and Hasher 2005; Riggle and Johnson 1996) found that older adults, as compared to younger adults, have slower information processing, shorter working memory span, and other cognitive changes that lead to using satisfying heuristics in which they did not use all information but made decisions that are "good enough" (i.e., satisfying).

Not all studies found correlations of age with decision making. For example, Passalacqua, (2004) did not find a correlation of patient age with effects of media information for healthcare decision making.

\subsubsection{Ethnicity/Ethnic Identification}

In trying to identify the effect of ethnicity on decision making, one of the observations is that

there is a fine line between race and ethnicity. Indeed, some studies (e.g., Kwak and Haley 2005) combine the two descriptors together, for example, they say "we reviewed the research literature on racial or ethnic diversity and end-of-life decision making in order to identify key findings and to provide recommendations for future research.” Depending on the specific study, being Hispanic-American, African-American, Asian-American, or European-American can be identified as an ethnic group or as a racial group. Ethnic groups are “.... any group which is defined or set off by race, religion, or national origin, or some combination of these categories," (Gordon 1964). 
Kwak and Haley (2005) did find differences among groups and suggest that "clinical care and policy should recognize the variety of values and preferences found among diverse racial or ethnic groups.” Cox et al. (1991) examined individuals from various ethnic groups including Asian-, Hispanic-, and Black-Americans and found that groups of people from collectivist cultural traditions showed more cooperative behavior than groups of individuals from individualistic cultural traditions. This again shows potential differences among ethnicity and behavior, including differences in decision making.

Ethnic identification has also been examined with regard to marketing of products. Webster (1990-91) found that different attitudes toward marketing practices were identified among Anglo-Americans and Hispanic subpopulations of Spanish-speaking and English-speaking families.

During this literature review, the researcher did identify an article describing the "ethnosizer," a measurement tool for the intensity of a person's ethnic identity (Constant et al. 2009). Such a measurement tool might be useful in the future if ethnic identity becomes an important variable in research.

\subsubsection{Education/School Level}

Education contributes to decision making by providing a better ability to obtain and use information efficiently. This was demonstrated in Huffman's (1974) study of farmers making decisions about crop production in which information is imperfect. Huffman found that education was positively related to the ability of farmers to adjust appropriately the amount of fertilizer used. Levinson et al. (2005) also found more educated individuals preferred to be more active in healthcare decision making than less educated individuals.

\subsubsection{Gender}

Gender is related to decision-making style (Martin et al. 2005). The authors found one study that identified girls as more likely to think about others, called a prosocial strategy, in decision making as compared with boys. There does seem to be some evidence that the two genders make different style decisions (see Passalacqua 2004 and Levinson et al. 2005) making gender a factor to include in the taxonomy.

\subsubsection{Marital Status}

The influence of marital status on decision making is less clear than some other demographic factors. Coyne and Anderson (1999), for example, found that, for married women, husbands were more involved and influential than other female relatives in decisions about genetic testing for breast cancer risk. Other research (e.g., Yellen and Cella 1995) did not find marital status to be a predictor of decision making in the case of health care treatment. 


\subsubsection{Military Demographics}

Military demographics (and the related demographic characteristics of rank, military status subgroups (reserve versus active), position (MOS), military training/schooling, time in service, role, is maintained within the taxonomy even though no specific information was found on the effects of military demographics on decision making. These are demographic factors that are unique to a military population and therefore seen as important to consider. This may be a gap in the literature where more information needs to be generated. It may also be that information specific to the military may be more difficult to find in open literature sources.

\subsubsection{Nationality}

Nationality is easily defined and gathered via interview. Nationality is often used as a variable in cultural impact studies. For example, Hofstede's classification of cultural dimensions has identified the degree that various nationalities exhibit those cultural dimensions (see http://geerthofstede.com/national-culture.html, for examples).

Other studies have used nationality as an independent variable to assess the effect of nationality on various kinds of decision making. For example, Loe et al. (2000) pulled together literature examining ethical decision making and found that there were mixed results regarding the effect of nationality. Within the 10 studies listed in the Loe et al. review, some of the studies had no significant differences among nationalities for ethical decision making. In other studies, there are some differences_-among nationalities in ethical decision making considerations, such as “foreign students are more ethical than US students" (Hegarty and Sims, 1978, cited in Loe et al., 2000) or "US managers consider ethical issues to be more important than UK managers" (Roberston and Schlegelmilch 1993, cited in Loe et al. 2000).

\subsubsection{Parenthood}

Another healthcare study on the influence of social factors on choosing aggressive cancer treatment showed that having children living at home was associated with more aggressive treatment preferences. Living with others also predicated more aggressive intent, although marital status did not predict acceptance of aggressive treatments (Yellen and Cella 1995). Parenthood, therefore, was shown to be associated with decision making on cancer treatment options.

\subsubsection{Place of Residence}

Passalacqua (2004) did find that place of residence was related to the effect of media information on healthcare decision making. This was a very specific finding. However, it does indicate that where one lives may be related to specific decisions made. While the place of residence may be an indicator, or correlated with, other data, such as socioeconomic status, the place of residence could be relatively easy data to gather. 


\subsubsection{Race}

Levinson et al. (2005) did find that, in this study, African-Americans and Hispanics were more likely to prefer a particular approach to health care decision making than other groups.

McKinley et al. (1996) found that African-American (black) and white individuals made different decisions regarding end-of-life care, such as the use of life-sustaining treatments and living wills, even when socioeconomic factors were controlled. The study examined possible reasons for the "ethnic differences", such as black patients trust the health care system less or feel less sure that living wills will give them control over end-of-life care.

Finucane et al. (2000) found that white males perceived risk less than others and the reasons may be quite complex. For the purposes of this taxonomy, the authors' work reported that risks are judged lower by white people than others and that men judged risk lower than women, showing that both race and gender made a difference in risk perception.

\subsubsection{Religion}

Research suggests that individuals with greater religiosity are more risk averse, as measured by financial measures of returns (Hilary and Hui 2009). Dyreng et al. (2012) examined how religious social norms (using religious adherence in the company headquarters' country). They found that high-religious adherence was associated with less tax avoidance and other financial reporting discrepancies, confirming the idea that religion influences economic choices and decision making. Loe et al. (2000) identified literature regarding the effect of various individual and organization factors on ethical decision making. There were mixed results on the effect of religion. Only 1 of the 3 studies identified within their review show that some strong religious beliefs were related to negative attitudes about some acceptable behaviors. The other 2 studies found no significant differences among different religious groups.

\subsubsection{Socioeconomic Status}

One of the issues with some of the demographic factors is that there can be correlations among factors, such as those who are in racial minority communities, may be socioeconomically disadvantaged and have less education (e.g., Feinstein 1993).

\subsection{Personality}

This taxonomy includes several traits in the area of personality. As presented earlier in Section 1.2.2., a trait is defined as a defining characteristic of a person. In this section, traits are discussed according to their definitions, the literature available, and why they are included in the taxonomy. 


\subsubsection{Trait Anxiety}

One of the more prevalent traits and one that is very predictive of state arousal is trait anxiety. Trait anxiety reflects the existence of stable individual differences in a predisposition to respond with state anxiety in the anticipation of threatening situations. It is closely related to the personality trait of 1 of the big 5, neuroticism. More recently, anxiety is linked to the need to choose between options. It is believed that, when people need to make a decision with too many options or not enough time to gather adequate information, they will experience state (or transient) anxiety. This state level will influence their abilities to make the decision. It is in this type of situation where their trait anxiety will mitigate or aggravate their arousal level. Additionally, trait positive affect or well-being is known to be a distinguishing factor between elite/non-elite combat units (Gal and Jones 1999).

\subsubsection{Fearfulness}

Fear is a vital response to physical and emotional danger to protect an individual from legitimate threats (http://www.psychologytoday.com/basics/fear). However, people often fear situations that are far from life-or-death so they tend to avoid any such situation. For example, they might fear public speaking or fear having to communicate with others. Although the literature addressing the effects of fear on decision making is limited, the study of fear itself is well researched. Fear is often associated with negative emotions, usually with anxiety. It is believed that persons prone to fear perceive threats are especially close to them (Perkins et al. 2010). Their fear is associated with defensive reactions that induce high levels of anxiety. Although fear and anxiety are believed to be separate emotions, they trade off as needed to provide the body's reactions as situations change. In this case, anxiety would take over and be accompanied by a "behavioral response of risk assessment." The Reinforcement Sensitive Theory (RST) postulates that the fight-flight-freeze system, the behavioral approach system, and the behavioral inhibition systems work together to mediate fear, the emotion of anticipatory pleasure, and anxiety. Together these systems work "paradigmatically between approach and avoidance, especially threatening stimuli that must be faced" (Perkins et al. 2010). Although humans are capable of retaining considerable amounts of information helpful to making a decision, they often forget to use that knowledge choosing instead to make decisions based on emotions (Sanbonmatsu and Fazio 1990). It is believed that expertise moderates the emotional decision-making process (Coget et al. 2011).

\subsubsection{Intelligence}

Because there are multiple types of intelligence, intelligence is discussed in general for the purposes of this taxonomy. Intelligence is a combination of 2 fundamental abilities: fluid ability and crystallized ability. Fluid ability is considered innate, as in basic reasoning skills. Crystallized ability is considered the information and skills acquired through experience in a cultural environment. 
In psychology research, intelligence can be defined as the totality of mental processes involved in adapting to the environment or as a "general mental ability involved in calculating, reasoning, perceiving relationships and analogies, learning quickly, storing and retrieving information, using language fluently, classifying, generalizing, and adjusting to new situations.”

(http://encyclopedia2.thefreedictionary.com/Intelligence+(trait))

Broder reported that intelligence determines which strategy people will use to make a decisions (2003). He stated that the more intelligent participants were more likely to make the simplest decision. Moreover, not only do they make rational decisions but they usually also maximize the expected benefits.

\subsubsection{Cognitive Flexibility (Handling Uncertainty)}

Ang et al. (2006) point out that cognitive adaptability or flexibility is predictive of performance on international work assignments. Understand this trait means knowing what cognitive flexibility means. In terms of traits, an individual's ability to handle uncertain situations will determine that individual's cognitive flexibility. Uncertainty is a mental state of having limited knowledge in which it is impossible to describe exactly the existing present or future outcomes and in which more than one possible outcome exists. Gal and Jones (1995) report that uncertainty takes on 2 forms in war: temporal uncertainty and event uncertainty. Temporal uncertainty involves knowing the event but not knowing when the event will occur. Event uncertainty involves knowing when the event will occur but not knowing the nature of the event. Although these issues tend to be acute in nature, an individual's innate ability to handle uncertainty will act as a mediator to the stress response.

Bar-Tal (1994) describes uncertainty as "the effect on mundane decision making of the need and ability to achieve cognitive structure.” According to recent research (Cosenzo et al. 2005), if a person's trait is reported as having a low need for cognitive structure and a high need for cognitive flexibility, then that person would be able to perform better in an unfamiliar, uncertain decision-making task. In contrast, a person whose trait is having a high need for cognitive structure and a low need for cognitive flexibility is less likely to perform better in an unfamiliar, uncertain decision making task. The trait of uncertainty, then, will mitigate or aggravate the state level of uncertainty. Grego and Roger (2003) report that uncertainty is related to individual differences and is of itself stressful. Tannert et al. (2007) developed a visual model of uncertainty. See Fig. 1. 


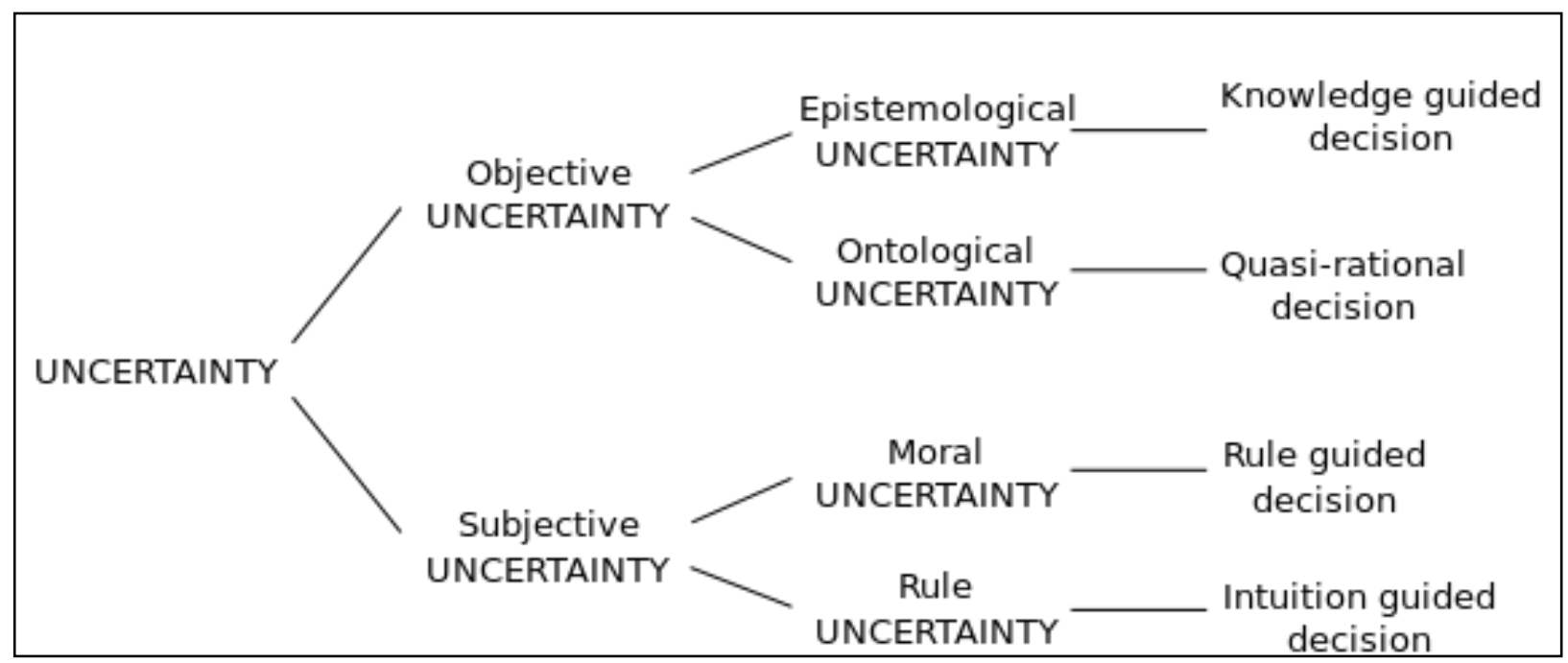

Fig. 1 Adapted from Tannert's visual model of uncertainty (freely available [in public domain] from http://en.wikipedia.org/wiki/File:Uncertainty.svg)

\subsubsection{Coping}

Within their psychological model of combat stress, Gal and Jones (1995) discuss the appraisal process as the "bridge" between the external factors and the Soldier's response to those factors. That it is a "combination of the soldier's perception and evaluation of both the situation and his/her own capability to cope with it.” Personality coping strategies are known to mitigate acute stress (Patton et al. in review). The mechanism an individual uses to cope with external or internal emotion will determine the outcome of the response to the situation. Lazarus and Folkman (1984) define coping as the "constantly changing cognitive and behavioral efforts to manage specific external and/or internal demands that are appraised as taxing or as exceeding the resources of the person.” Vitaliano et al. (1987) validated the Revised Ways of Coping questionnaire that measures an individual's coping personality.

Coping personality is an individual's characteristic strategy to use in response to acute stressors. The coping styles identified in this questionnaire are: Problem Focused, Avoidance, Wishful Thinking, Seeking Social Support, and Blaming Self. Of these styles, aggressive coping mechanisms, problem focused, and seeking social support are predictive of better performance versus the more maladaptive coping mechanisms, wishful thinking, avoidance, and blaming self (Patton et al. in review; Fatkin and Patton, 2008).

\subsubsection{Self-Efficacy (Confidence)}

According to Bandura (1995), an individual's self-efficacy determines if a coping behavior will be initiated. For Bandura (1995), self-efficacy is the belief people have in their abilities to control events that affect their lives. Self-efficacy has 3 components: 1) magnitude, which refers to belief about performance in increasingly difficult aspects of the task; 2) strength, or the effort expended to maintain the behavior in the face of obstacles; and 3) generality, or the broadness of the applicability of the belief. Human behavior is affected by self-efficacy beliefs through 
cognitive, motivational, affective, and decisional processes (Bandura and Locke 2003). It is believed that self-efficacy is the most central and pervasive mechanisms of the human agencies. The core belief that guides and motivates an individual's actions is self-efficacy; without selfefficacy, individuals have little incentive to act or continue when facing challenges. According to Bandura (1997), people with high self-efficacy in their abilities to make decisions are more effective in making complex decisions. Thus, efficacy results in better solutions and in more successful outcomes.

\subsubsection{Motivation}

Motivation is closely tied to self-efficacy. Motivation can be defined as a process that elicits, controls, and maintains certain behaviors. Azari et al. (2010) discuss how differences in Soldier's motivations may mitigate the effects of cultural stress. Moreover, Azari et al. (2010) believe motivation can also help manage cultural stress, possibly even preventing cultural stress. There are 2 distinct types of motivation: intrinsic and extrinsic. Intrinsic motivation refers to motivation that comes from inside individuals, such as an action that makes them feel good to complete versus receiving some sort of external reward for completing that action. Extrinsic motivation then refers to motivation that comes from external sources, such as from receiving money or making good grades, or being promoted. According to the Self-Determination Theory (SDT) "extrinsic motivation can be internalized by the individual if the task fits with their values and beliefs and therefore helps to fulfill their basic psychological needs” (Deci and Ryan 1985). This description shows that, while intrinsic and extrinsic motivations are different, there are times when extrinsic motivation can become intrinsic motivation. SDT focuses on the degree to which an individual's behavior is self-motivated and self-determined and is the macro theory of human motivation and personality, concerning people's inherent growth tendencies, and their innate psychological needs. It is concerned with the motivation behind the choices that people make without any external influence and interference (Deci and Ryan 1985).

Botelho and Coelho (1996) suggest that a significant relation exists between "effort allocated to the decision process and the motivation of the decision maker”. Forgas (1992, 1994, 2001) developed a model with 4 distinct styles of decision making. These styles correspond with 4 information-processing strategies: "direct access to stored information, heuristic information processing, motivated information processing, and substantive information processing.” Botelho and Coelho (1996) believe that decisions are made based on motivation to search for information and that information may be in long-term memory or not available yet. Motivation also influences if information will be ignored and what information will be ignored. This motivation is influenced by the need for the desired outcome, desire for structure, and the need for accuracy or achievement.

\subsubsection{Need for Achievement}

The need for achievement is believed to influence goal setting. Reports of higher standards or higher goal setting have shown a positive correlation with personal ability (Phillips and Gully 
1997). The business community describes the need for achievement as a trait characterized by an enduring and consistent concern with setting and meeting high standards of achievement. This need is influenced by an internal drive for action (intrinsic motivation) and by the pressure exerted by the expectations of others (extrinsic motivation). Measured by thematic appreciation tests, need for achievement motivates an individual to succeed in competition and to excel in activities important to him or her (http://www.businessdictionary.com/definition/need-forachievement.html). Thus the need for achievement is closely related to if not driven by motivation, both intrinsic and extrinsic and therefore a factor that affects decision making.

\subsubsection{Locus of Control}

Locus of control (LOC) is believed to be either internal or external belief. Internal LOC refers to the belief that individuals' own behaviors determine the rewards they obtain. External LOC refers to the belief that individuals' own behavior does not matter; rewards afforded are generally outside their control (Rotter 1966). Rotter (2006) states the men are more inclined to have an internal LOC compared to women. He (Rotter 2006) also states that, in general, an internal LOC is seen as more desirable. The LOC influences how a person makes decisions. A more general LOC is predictive of behavior in novel, unknown situations; a state-like LOC is predictive of behavior in more structured settings (Anderson et al. 2005). Those who make decisions on their own tend be more internal while those considered having an external LOC make decisions based more on what they feel others want. External LOCs tend to be more stressed and depressed because of their awareness with the situation and life strains (Rotter 2006).

\subsubsection{Sensation Seeking}

Sensation seeking is an individual's desire for varied, complex, novel, and intense stimulation. It is believed that men are more likely to be high-sensation seekers than women. It is believed that sensation seeking and decision making are harmonious in the decision-making process (Donohew et al. 2000). Research shows that high-sensation seekers who partake in risky situations may also make impulsive decisions. Low-sensation seekers tend to make rational decisions by using beliefs about consequences compared to the high-sensation seeker who make decisions based on effect and physiological cues (Donohew et al. 2000). Zuckerman (1971) states that high sensation seekers have lower levels of monoamine oxidase (MAO) type B, an enzyme involved in the regulation of neurotransmitters, particularly dopamine.

Dehydroepiandrosterone (DHEA) is believed to enhance the acquisition and consolidation stages of memory in animal models of memory and, as such, may play a role in age-dependent cognitive decline. MAO and DHEA peak in the late teens and early 20s (a large percentage of the military is in this range) and gradually declines with age as do levels of testosterone. MAO, which is low in high-sensation seekers, increases in the blood and the brain with age. Research is currently being conducted to investigate the effects of DHEA supplementation on performance in extreme environments. Interestingly, in years of research conducted by the ARL-HRED, Soldiers 
tend to report higher baseline sensation seeking compared to non-Soldiers (Fatkin and Patton, 2008).

\subsubsection{Empathy}

Empathy is defined as a "process of humanizing objects, of reading or feeling ourselves into them" (Titchener 1924). Others believe empathy has an affective component and yet others believe empathy has/contains a cognitive component. It is believed to play a central role in social interaction. Empathy can either be innate or taught, that is, a person can be taught to be more empathetic. Narcissists and psychopaths do not show empathy or have the capability to be empathetic. There is not a clear definition that determines empathy as a true trait but rather defines empathy more as a capacity. The capability to show empathy is known to play a key role in social relationships. Most research on empathy and decision making revolves around ethical decisions, such as decisions made in the medical field. Other research involves rape cases. Olsen-Fulero and Fulero (1997) research the ways empathy affects decision making in a military context or empathy in general is limited in a military context. Empathy is worth investigation; therefore, it is part of this taxonomy.

\subsection{Experience}

This section describes the research identified in the literature that demonstrates support for each specific experience factor having a relationship with decision making. Experience can be attained either by unstructured natural acquisition or by regimented programming. It is important to note that the idiosyncrasies of a culture like gestures, traditional posturing, and greetings cannot be learned in half-day classroom presentations or through general culture training. Certain elements of culture are best learned through practice, by immersion, or through simulation training.

\subsubsection{Cultural Exposure}

Cultural exposure is critical in establishing the image of the military to the host population because it facilitates positive cross-cultural interaction. Cultural exposure contributes to decision making by providing a viewpoint from which the decision-making process begins. It is defined as experiences related to a region that aid in developing a familiarity with or understanding of the norms, values, and beliefs of that region and is likely to contribute to higher cultural intelligence (Crowne 2008). Natural acquisition cultural training or cultural exposure can be further subdivided into the following categories: family culture, interactions with multiple cultures, previous occupation, and travel. All of these experience methods are considered informal whereas cultural knowledge is acquired through life experiences. The first teacher of culture is the family. Family tradition often coincides with that of the greater cultural group and is passed down from generation to generation. The household environment and ethnic culture in which individuals are raised greatly defines and shapes their core values of self and their ability to relate to people of other cultures. Hsee and Weber (1999) found that the inherent influence of 
culture affects basic judgment, decision making, and, rightly, risk preference. Their study demonstrated that the Chinese were significantly more risk seeking than Americans. It has also been demonstrated that various ethnic groups are more or less likely to take risks (Vrendenburgh and Cohen 1995), thereby affecting the decision-making processes of individuals of those groups.

Experiential learning enhances people's knowledge by providing a large, almost intuitive foundational skill set from which to draw when making decisions. Knowledge learned through environments, such as work, travel, and family expand cultural intelligence by influencing perception and perspective taking, which is/are fundamental to social interaction and decision making. A study investigating decision response times in a dynamic tactical scenario found that participants with greater command-post experience knowledge took longer to assess a situation than the less experienced participants group yet took less time to select a course of action than the less experienced group, thus further demonstrating that exposure to experiences influences decision processing (Kobus et al. 2000). The natural acquisition method of cultural awareness and understanding is partially sufficient when working in multicultural and multinational environments. Formal training in communicative, behavioral, and attitudinal skills are required in addition to cultural exposure for successful interaction with individuals of other cultures.

\subsubsection{Cultural Training (General)}

Current military language and culture strategies aim at building and maintaining a comprehensive approach to increasing cultural and language skills and regional expertise to close gaps in capabilities for facilitating successful operations. The military institutes specific language and culture strategies aimed at building and maintaining a comprehensive approach to increasing cultural and language skills and regional expertise to close gaps in capabilities to facilitate successful operations. The TRADOC_-TCC educates Soldiers in cultural competency through 2 broad approach areas typical of most culture training: general culture training and region specific culture training. These 2 types of formal culture training (culture general and region specific) should be experienced to increase one's cultural awareness. General cultural training teaches about a culture by identifying the points on which cultures vary, providing a framework to consider cultural similarities and differences while region specific focuses on particular locales Abbe and Halpin (2010). Culture general training does not provide the agility needed to adjust to local conditions but it does improve cultural intelligence. Research shows that low cultural intelligence can lead to problems in new cultural settings; miscommunication, insult, embarrassment, etc. (Crowne 2008). General culture training provides the framework for comprehending region-specific training and ultimately improves decision making. Culture general training was included as part of this taxonomy because the type and level of cultural education influences perception and therefore decision making. 


\subsubsection{Cultural Training (Region-Specific)}

Region-specific cultural training provides descriptive facts and figures about a locale, conveying information of immediate relevance on a mission required, as-needed basis while culture general teaches the points on which cultures vary, providing a framework to consider cultural similarities and differences and helping to inform decisions (Abbe and Halpin 2010). Region specific training does not provide knowledge that may be easily transferable or applicable to other regions. It focuses on the specific descriptive facts and figures of a region's government, history, and development, which would prove meaningless in a mission centered on another region of the same culture area. Region specific training may provide information that may be too specific and may not include the most up-to-date cultural information for a region but is still beneficial given the complexity of social cultural factors in decision making.

\subsubsection{Expertise}

Expertise is considered a subcomponent of experience because, without experience, people would not achieve a level of proficiency in a respective area to attain the level of expert in. Regional and technical expertise are considered experience factors because research shows people both under and over utilize automated aids (Parasuraman and Riley 1997). Cultural influences may affect how people in a culture use and trust technology (Adams and Bruyn 2003). This factor was included because experience, exposure, and education shape individuals personal cultural attitude and is reflected in their interaction with people from other cultures. An expertise in a foreign language, technology, occupational field, etc., may be associated with decision making.

\subsection{Context}

This section describes the research identified in the literature that demonstrates support for each specific context factor having a relationship with decision making.

\subsubsection{Information Context}

The amount of information available to a decision maker (information quantity) and the goodness of that information (information quality) can influence decision making greatly. A study conducted by Glazer et al. (1992) revealed that the presence of irrelevant information (basically excess information) can cause decision makers to be distracted and therefore take more time to make a decision even in situations where the information is interpreted correctly. Although the irrelevant information did not lead to incorrect decisions, it did cause the decision makers to take significantly longer to make their decision, which can be time critical in a military context. While intuitively it would be expected that data regarding information quality would be useful to decision makers, studies conducted by Chengalur-Smith et al. (1999) suggest that information concerning the quality of the data being provided may be counterproductive in complex decision-making environments. The inclusion of this data could lead to information 
overload in a complex decision-making environment but could be beneficial in more simple decision-making environments.

\subsubsection{Media Environment}

The media's goal is to keep the public informed in a timely manner and to remain competitive with respect to the other media organizations. The military wants to maintain operational security for the success of the mission and the safety of the troops. Many times there has been conflict between the 2 groups because of their differing missions. Despite these conflicts in the past, the US military needs to understand the media environment and plan carefully for media involvement in any future contingency (Goebel 1995). When discussing the role of the media, the term, CNN Effect, is often identified as a relevant phenomenon that can drive foreign policy and decision making. The CNN effect is described as the effect that real-time news media has on politics and government during political conflict and natural disasters (Livingston 1997). The media's role in influencing national and international public opinion has grown immensely over the past decade with the evolution of computers and the extensive use of social media.

Pinkleton and Austin (2002) conducted a study surveying 592 registered voters in Washington State that tested a set of relationships among political involvement, perceived media importance, political disaffection, and efficacy. Political involvement was positively associated with the perceived importance of newspapers and radio talk shows. Perceived media importance also was associated directly with increased efficacy. These results suggest that the media can serve as a catalyst for involved political decision making when they provide information that is clearly relevant to citizens' lives and the public affairs issues they consider (Pinkleton and Austin 2001).

\subsubsection{Mission Context}

The literature discusses the importance of the military as a social institution and how it affects people's lives, both directly and indirectly, as well as how it effects other institutions (Segal 1999). The central role of the military is to protect and defend the Constitution, ensure the security of the US, and advance national policies (Department of Defense 2010). However, when trying to understand the importance of the role that the military plays in decision making, it is key to think in terms of mission context. Mission context is any information that can be used to characterize the military situation of a place, object, person, or group of people that is considered relevant to the mission (Poltrock et al. 2009). Components of unified land operations or missions are offense, defense, stability, and civil support (Headquarters, Department of the Army 2012). Within unified land operations the tasks within each component are the following. 
- Offense

o Movement to contact

o Attack

o Exploitation

o Pursuit

- Defense

o Area defense

o Mobile defense

o Retrograde

- Stability

o Civil security

o Civil control

o Restore essential services

o Support to governance

o Support to economic and infrastructure development

- Civil support

o Provide support in response to disaster

o Support civil law enforcement

o Provide other support as required

o Support for domestic chemical, biological, radiological, and nuclear incidents

\subsubsection{Physical Environment}

The physical environment is the external surroundings and conditions in which something exists. An urban terrain consisting of buildings and landscaping would be a physical environment that Soldiers face during a variety of military missions. Items of the physical environment, such as the terrain, weather, and the presence of combatants and non-combatants, can greatly affect Soldier and Commander decision making. The physical environment is identified as a critical issue specifically in peace operations because climate and terrain can affect the success of the mission (Pirnie and Simons 1996). Research in the area of environmental psychology support the notion that environmental stimulus affects the emotional state and behavior of people. For example, a study conducted by Baker et al. (1992) demonstrated that specific ambient and social factors (music and lighting; presence of friendly sales associates) affected the consumer's decision to make purchases. These results might suggest that the physical environment of the Soldier and the Commander may influence their decision making.

\subsubsection{Political Context}

Political context reflects the environment in which something is produced, which indicates the purpose or agenda of that production/item. It also refers to the political aspects of the environment that are relevant to action. These aspects include the distribution of power, the range of organizations involved and their interests, and the formal and informal rules that govern the interactions among different players (Nash et al. 2006). Political context may also be referred to as socio-political context. Politics can be described as the process by which groups representing divergent interests and values make collective decisions. 
A similar term to consider is political climate. Political climate is the aggregate, current mood, and opinions of a populace about political issues that also currently affect that population. Political climate is generally used to describe a state of change in mood and opinions rather than a state of equilibrium.

\subsubsection{Social Context}

Social context can be described as the psychological position to which people react in different ways, depending on their immediate environment. (http://answers.reference.com/information/ terminology/what_is_the_meaning_of_social_context). Social context can be influenced by several factors, such as social power, group dynamics, grouping, organizational size, collective identification, and trust.

Social Power is society's perception of the influence individuals possess or the perception individuals possess of their own influence. Social power can affect decision making. Several studies conducted by Fischer et al. (2011) concluded that those decision makers who felt more social power were more confident in their decisions. In turn, this confidence led to a behavior called confirmatory information processing. Confirmatory information processing is a behavior in which individuals are inclined to pay more attention to information that supports their initial decision than to information that contradicts it. A study by Galinsky et al. (2006) revealed that people with a lot of social power are less likely to view a situation from other's perspective relying instead more on heuristics. These studies and others indicate an influence of social context on decision making.

Group Dynamics is a system of how group members interact and influence each other and their processes to accomplish a task or mission. Within a group, there exist individual roles, group standards (the rules by which it operates), and level cohesiveness (what causes an individual to remain in the group) (University of Kentucky 2012). Level cohesiveness can be greatly affected by collective identification, that is, the members of the group perceive they belong to that group. National and organizational cultural identification, how people perceive their relationship to country and work ranges from individualism to collectivism and varies between cultures. People within high-individualism groups have weaker connections than groups with collectivism who exhibit strong cohesion, loyalty, and harmony (Langerholc 2010). Collective identification is defined as an individual's perceived membership in a social group that impacts the individual's identity in some way. The individual mind versus the networking of multiple individuals influences both the group thought process as well as the individual's thought process. The longer the association or group affiliation, the more cohesive and conformist the individual is to the group (University of Kentucky 2012). Put in the contect of Warfighters, this group identification provides strength whereby individuals in a group environment willingly make decisions and take risks they would not have taken had they not had the support of, or affiliation to, their group. The radical form of collective identification is collective narcissism. Collective narcissism 
is an emotional investment in an unrealistic belief of group greatness (Golec de Zavala et al. 2007). Members within this type of group tend to act aggressively to out-groups, believing in group superiority. Well-known historical examples of collective narcissism are the Holocaust (Nazis belief in self-superiority), and Abu Ghraib (American Soldier abuse of prisoners) where the in-group demonstrated extreme forms of aggression to the out-group. The US military has a high sense of self, which may affect multinational and joint force operations. These studies and others indicate that group dynamics affect individual and group decision making.

Grouping and Organization Size in this taxonomy describes how the decision makers are aligned to work together and the number of members of the team that they work in. In today's military environment and in future ones, decision making is happening at lower levels sometimes by the individual Soldier. Individual Soldiers have always had some level of decision making particularly in regard to their own personal security (friend or foe, life threatening). The military decision maker tends to be isolated but does have the occasion to seek advice or counsel when appropriate. Much of military work, however, is conducted in a team environment. Grouping research can support the understanding of team decision making.

Jessup and Tansik (1991) conducted a study to examine the effects of anonymity and proximity on decision making using a group decision support system. Their results revealed that individuals working anonymously and dispersed made more comments and questioned others' solutions more than those working in a face-to-face identified known environment. They also demonstrated that individuals working in the face-to-face condition reported higher levels of satisfaction than those working in the distributed environment. Participants working in the anonymity condition reported that the system was more helpful and effective than previous faceto-face problem solving sessions. Participants working in the identifiable condition reported the system less effective and helpful. As the military environment becomes more and more distributed and as Soldiers will need to rely on data and information from sources outside of their teams in these new cultural environments, this type of research becomes more relevant than it may have been in Cold War military environments.

In several studies of how advice is used in decision making, Yaniv (2004) revealed that decision makers tend to discount the advice of others, except in situations where the decision maker was less knowledgeable. In those cases, decision makers then tended to weight the value of the advice higher than those decision makers who were more knowledgeable.

Trust is integral in team working environments, especially in the military where team members are entrusted with protecting each other's lives. Trust concerns occur in situations involving dependence on others and in situations involving risk and uncertainty. Trust is derived partly from the members of a group accepting a standard and adhering to it, similar to a trait of group dynamic (Kirkland 2003). The Oxford English dictionary defines trust as "the firm belief in the reliability, truth, or ability of someone or something," Yet there are varying degrees of trust. The concept of trust in groups or between individuals differs because of the nature of the 
relationships, such as in differences in social standing. Examples of group trust include interpersonal, intra-personal, inter-team, inter-organization, intra-organization, and distributed versus co-located (Stanton 2011).

\subsubsection{Temporal Context}

The temporal context is defined by factors affecting the time available to make a decision. Time pressure can be defined as the psychological burden to complete some action within a perceived shorted timeframe. While most time pressure effects on decision-making studies are conducted in static environments, Kerstholt (1994) examined the effect of time pressure on decision making in a dynamic environment. A dynamic environment is characterized by continuous changes over time while information is provided on changes in the system state. Continuous change is very representative of military environments. In the Kerstholt (1994) study, participants imagined that they were serving as a personal attendant to an athlete running a race. As such, they were required to monitor the fitness level of the athlete and interject mediation when the athlete's fitness level was decreased. The results indicated that the participant's decision-making strategy differed when time pressure was increased. Participants spent less time processing information. This research and other studies examine time pressure along with risk taking (Dror et al. 1999). Risk taking is represented in the taxonomy as a part of sensation seeking.

In a study examining the effectiveness of icons to support distributed team decision making under time pressure, Adelman et al. (2004) uncovered that, during conditions of higher time pressure, participants increasingly made decisions without having the critical information necessary to ensure a more accurate performance. These results demonstrated a shift in decisionmaking strategy as time pressure increased.

\section{Proposed Model and General Framework}

Now that the taxonomy has been explained, this next section lays out how the taxonomy fits into a general framework of the effects of sociocultural factors on decision making. Figure 2 depicts the initial framework concept of how the sociocultural factors described in this report affect decision making. 


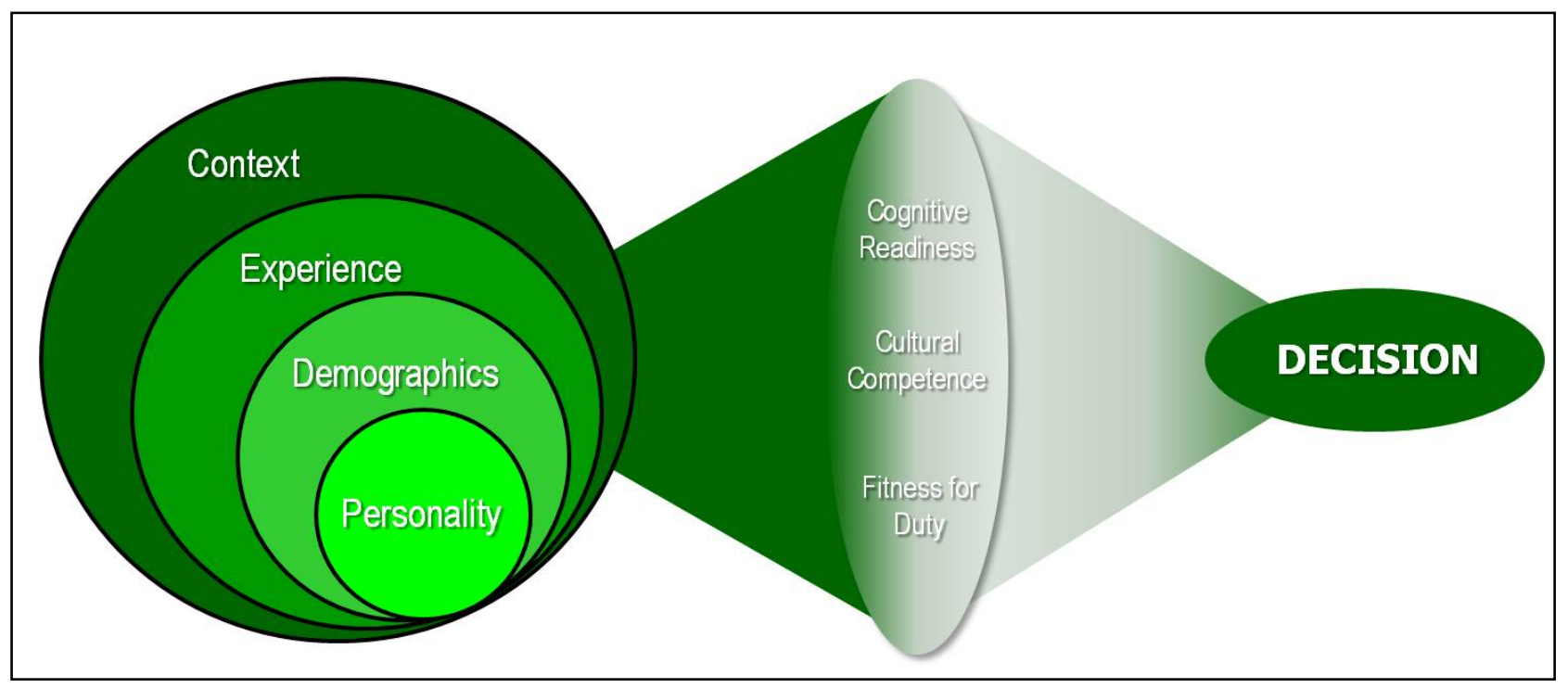

Fig. 2 General framework of the influence of sociocultural factors on decision making

This general framework translates the proposed affect of the sociocultural factors on decision making. First, the taxonomy defines Soldier and Commander makeup in the contextual environment in which they are placed. The 4 taxonomic elements (demographics, personality, experience, and context) define an individual's approach to decision making. These factors then lead them to particular states at a certain level in 3 areas; cognitive readiness, cultural competence, and fitness for duty. Depending on their level of each of these states leads them to a particular decision being made that results in some action. Their particular decision-making results in action depending on their level of each of these states.

\subsection{Cognitive Readiness}

Cognitive readiness is defined as "possessing the psychological (mental) and sociological (social) knowledge, skills, and attitudes that individuals and team members need to sustain competent professional performance and mental well being in the dynamic, complex, and unpredictable environments of military operations” (Bolstad et al. 2006). Cognitive readiness is influenced by a range of varying characteristics. Components of cognitive readiness include (but are not limited to) situation awareness, memory, transfer of training, meta-cognition, automaticity, problem solving, decision making, mental flexibility and creativity, leadership, and emotion (Morrison and Fletcher 2002). Other components include cognitive resources, perception, attention, physical and mental condition, knowledge, and attitudes (Bolstad et al. 2006). The importance of Warfighter cognitive readiness is that mental agility and continued strength are a necessity in dealing with the rigors of military life and combat operations.

\subsection{Cultural Competence}

Cross cultural competence is defined as the development of knowledge and skills through experience and training that result in a complex schema of cultural differences, perspectivetaking skills, and interpersonal skills. This schema can be demonstrated through the willingness 
to engage in new environments even in the face of considerate ambiguity, through selfmonitoring and through self-regulation to support mission success in a dynamic context (Ross 2008). Wunderie (2007) defines cultural competence as the fusion of cultural understanding with cultural intelligence that allows focused insight into current operations by inferring insight into the intentions of specific actor and groups. Both Ross' and Wunderie's definitions of cross cultural competence identify the following components: 1) awareness of one's own culture, 2) adaptive perspective taking, and 3) the application of knowledge to an ongoing situation.

\subsection{Fitness for Duty}

Fitness for duty is the capacity to which a person is fit to serve in his or her job capacity. Whether or not that person is trustworthy, will perform his or her tasks in a reliable manner, are not under the influence of any substance, and are not mentally or physically impaired are factors that are considered when determining fitness for duty. In determining fitness for duty, it is important to understand any cause that can adversely affect a person's ability to safely and competently perform his or her duties (US Nuclear Regulatory Commission 2012). Factors, such as fatigue and substance abuse, can influence fitness for duty but are beyond the scope considered in this framework.

These 3 states have been identified as the lens through which decision making is affected by sociocultural factors. However, there will also be interactions among these 3 states that are not fully defined currently. For example, if fitness for duty is low because of fatigue, that will also affect an individual's cognitive readiness although it may not affect their cultural competence. What is important here, though, is that the demographic, personality, experience, and contextual factors will result in a level of cognitive readiness, fitness for duty, and cultural competence that will greatly influence decision making.

\section{Additional Items for Consideration}

There are also other sociocultural factors that the researchers believe are influential to decision making but were not added to the taxonomy. The factor of values, for instance, seems to be vitally important to decision making but is difficult to quantify and to pull apart from other factors, such as some identified in personality (e.g., self-efficacy) and demographics (e.g., religion). Another factor related to sociocultural factors impact on decision making is "perspective taking". While someone's ability to do perspective taking is influential in how he or she make decisions, it is not a factor that can be measured as of yet. This section explains these 2 factors. 


\subsection{Values Congruence}

The common dictionary definition of a value is "something (as a principle or quality) intrinsically valuable or desirable” while the Dictionary of Human Geography defines values as "the principles or standards informing individual or group ideas and beliefs." Values have also been coined as ethics, morals, and cultural values.

"Cultural differences are reflected in values, which in turn affect behavior, including the way in which decisions are made.” (Albaum et al. 2010). O’Boyle (1996) claims that “...values are never random. They are the products of culture, the complex adaptive system the brain uses to help meet universal needs within a specific environment.” Research in ethical decision making and culture often use Hofstede's dimensions applied to business and healthcare settings (Robertson and Fadil 1999; McLaughlin and Braun 1998).

The most prolific researcher in cultural values is Shalom Schwartz. He summarized the focus of decades of work on basic values as follows:

1) Values are beliefs that are linked inextricably to effect.

2) Values refer to desirable goals that motivate action.

3) Values transcend specific actions and situations. This feature distinguishes values from narrower concepts, such as norms and attitudes that usually refer to specific actions, objects, or situations.

4) Values are standards or criteria that guide selection or evaluation of actions, policies, people, and events.

5) Values are ordered by importance relative to one another to form a system of priorities. This hierarchical feature also distinguished values from norms and attitudes.

6) The relative importance of values guides action (Schwartz 2007).

Schwartz (2007) defines 7 cultural dimensions: Harmony, characterized by unity with nature and a world at peace; Embeddedness, social order, obedience, and a respect for tradition; Hierarchy, submission to authority; Mastery, ambition and daring; Affective Autonomy, taking pleasure; Intellectual Autonomy, broadmindedness and curiosity; and Egalitarianism, social justice and equality. These dimensions are grouped into three bi-polar relationships: Embeddedness versus Autonomy (Affective and Intellectual), Hierarchy versus Egalitarianism, and Mastery versus Harmony. The theory further defines 10 motivational types of values: power, achievement, hedonism, stimulation, self-direction, universalism, benevolence, tradition, conformity, and security (Ros et al.1999; Davidov et al. 2008).

Schwartz and other researchers have used his theory (Schwartz 1992) to compare national cultures and subcultures. Forty-four countries were co-plotted along the 7 dimension and the implications for attitudes about work have been studied (Schwartz 1999). Munene et al. (2000) 
examined the relationship between cultural values and socioeconomic development, especially in sub-Saharan Africa.

There is a growing literature in the study of cultural values and decision making in consumer and business spheres. For example, McLaughlin and Braun (1998) discuss the implications for healthcare research and practice when collectivist cultural values come in conflict with the individualistic nature of the American medical community. Five case studies highlighting ethical and cultural issues impact on mental health care decisions are described by Hoop et al. (2008). Srnka (2004) examines marketing ethics theory in a multicultural global marketplace. Also, the effect of cultural values on business ethics and international decision making was discussed in the Journal of Business Ethics (Vitell et al.1993). While these and many other examples are available for examining the practical application of cultural values, no studies were found specifically involving military decision making.

\subsection{Perspective Taking}

Perspective taking (also known as Social Perspective Taking [SPT]) is one of the steps preceding decision making. Gehlbach (2004) defined it as the skill requiring a combination of cognitive and affective/emotional skills and the propensity or motivation to engage in the activity. Johnson (1975) recognized perspective taking as the ability to understand how a situation appears to another person and how that person is reacting emotionally and cognitively to the situation. The importance of SPT is demonstrated with its benefits, which are most critical in a military environment. In military settings, leaders are required to understand their subordinates, the enemy, the local population, and allies in order to successfully complete missions (US Department of Army 2006). Adequate perspective taking reduces stereotyping, thereby improving group dynamics and increasing mission success (Galinsky and Moskowitz 2000). The increase in social understanding also helps to facilitate conflict resolution (Deutsch, 1993).

Researchers suggest that there are 2 common theories of perspective taking: simulation theory and implicit theory (Reeder and Trafimow 2005). Simulation theory involves placing one's self in another person's mental state, while implicit theory relies on drawing on general knowledge to infer another's mental state. Simulation theory is an interpersonal technique learned throughout life but can be difficult to use in cross-cultural interactions because of the complex issues involving customs, rights, etc., especially because most Soldiers have little cross cultural experience (Roan et al. 2009). One person can always simulate being in "someone else's shoes," but how realistic is the exercise, as people tend to relate to situations in terms of their own experiences and culture. Norenzayan and Nesbitt (2000) corroborate this in their forth basic cognitive commonality: because people have differing cultural worlds of influence (i.e., social, economic), their beliefs and values are potentially different as well. 


\section{Conclusions}

This technical report outlines the first step in the ARL HRED RISC-D program to develop a taxonomy of sociocultural factors that influence decision making. This report also outlines an initial framework for how the taxonomic factors affect decision making. The next step in this research program is validation. To obtain face validity of the taxonomy and framework, ARL HRED will continue to introduce the taxonomy draft to researchers in the area of decision making, specifically in military decision making. The opinions of social scientists, psychologists, and other decision-making experts will be used to identify any discrepancies. Once all subject matter expert feedback has been incorporated, exposure of the taxonomy to Soldiers and Commanders will begin. Because the researchers are attempting to determine how sociocultural factors influence decision making, the procedure for examining construct validity must help to identify this influence. This influence may be obscure to the actual decision maker. An initial idea for this validation study would be to conduct an online survey. During the online survey, data would be collected by administering questionnaires that measure each decision maker's level on each of the sociocultural factors. Then, each participant will be placed in an experimental decision-making environment to understand how decision-making performance varies across the various levels of each factor. This approach should yield data to support a level of face and construct validity that are essential to ensuring the taxonomy is valid enough to be used for the development of a sociocultural influenced model of decision making - a future goal of this research effort. 


\section{References}

Abbe A, Halpin, S. The Cultural imperative for professional military education and leader development. Parameters 39 (Winter 2009-2010):20-31 Print.

Adams BD, Bruyn LE, Houde S. Trust in automated systems literature review (Report to Department of National Defence, DRDC No. CR-2003-096). Toronto, ON: Defence Research and Development Canada, 2003.

Adelman L, Miller S. Yeo C. Testing the Effectiveness of Icons for Supporting Distributed Team Decision Making Under Time Pressure. IEEE Transactions on Systems, Man and Cybernetics-Part A: Systems and Humans. 2004;34(2);179-189.

Albaum G, Yu J, Wiese N, Herche J, Evangelista F, Murphy B. Culture-based values and management style of marketing decision makers in six western pacific rim countries. Journal of Global Marketing. 2010;23,139-151.

Almotairi M. CRM Success Factors Taxonomy. European and Mediterranean Conference on Information Systems. Al Bustan Rotana Hotel, Dubai, May 25-26, 2008.

Alonso-Rios D, Vazquez-Garcia A, Mosqueira-Rey E, Moret-Bonillo V. A context-of-use taxonomy for usability studies. International Journal of Human-Computer Interaction 2010;26(10); 941-970.

Anderson A, Hattie J, Hamilton R J. Locus of control, self-efficacy, and motivation in different schools: Is moderation the key to success? Educational Psychology. 2005:25,517-535.

Ang S, Van Dyne L, Koh C. Personality Correlates of the Four-Factor Model of Cultural Intelligence. Group \& Organization Management. 2006;31(1):100123.doi:10.1177/1059601105275267

Azari J, Dandeker C, Greenberg N. Cultural Stress: How interactions with and among foreign populations affect military personnel. Armed Forces \& Society. 2010;36(4): 585-603. [accessed 2015 Jan 28] http://afs.sagepub.com/cgi/content/abstract/36/4/585

Baker J, Levy M, Grewal D. An Experimental Approach to Making Retail Store Environmental Decisions. Journal of Retailing. 1992;68-4, 445-460.

Bandura A, Locke E. Negative self-efficacy and goal effects revisited. Journal of Applied Psychology. 2003;88,87-99.

Bandura A. Self-efficacy in changing societies. New York: Cambridge University Press, 1995. 
Bandura, A. Self-efficacy: Toward a Unifying Theory of Behavioral Change. Psychological Review. 1977;84(2): 191-215.

Bar-Tal Y. The effect of mundane decision making of the need and ability to achieve cognitive structure. European Journal of Personality. 1994; 8,45-53.

Bodenhausen GV, Wyer RS, Jr. Effects of stereotypes on decision making and informationprocessing strategies. Journal of Personality and Social Psychology. 1985;48, 267-282.

Bolstad CA, Cuevas HM, Babbitt BA, Semple CA, Vestewig RE Predicting Cognitive Readiness of Military Health Teams. Presented at the International Association of 16thWorld Congress Maastricht, Netherlands, 2006.

Botelho LM, Coelho H. Information processing, motivation and decision making. In Ein-Dor, P. (ed.) Artificial Intelligence in Economics and management” (AIEM'96), p233-250, Kluwer Academic Publishers, London, 1996.

Broder, A. Decision making with the "adaptive toolbox": Influence of environmental structure, intelligence, and working memory load. Journal of Experimental Psychology: Learning, Memory and Cognition. 2003;29,611-625.

Carter C, Kaufmann L, Michel A. Behavioral supply management: a taxonomy of judgment and decision-making biases. International Journal of Physical Distribution and Logistics Management. 2007;37(8):631-669.

Chen Y, Sun Y. Age differences in financial decision making: using simple heuristics. Educational Gerontology. 2003; 29:627-635.

Chengalur-Smith I, Ballou D, Pazer H. The impact of data quality information on decision making: an exploratory analysis. IEEE Transactions on Knowledge and Data Engineering. 1999;11(6):853-864.

Coget JF, Haag C, Gibson D. European Management Journal (can find the full reference - need library help). 2011.

Constant A, Gataullina L, Zimmerman K. Ethosizing immigrants. Journal of Economic Behavior and Organization. 2009;69,274-87.

Cosenzo KA, Fatkin LM, Branscome T. Cognitive uncertainty and work shifts in a real-world multi-task environment. Aberdeen Proving Ground (MD): Army Research Laboratory (US); May 2005. Report No.:ARL-TR-.

Cox TH, Lobel SA, McLeod PL. Effects of Ethnic Group Cultural Differences on Cooperative and Competitive Behavior on a Group Task, The Academy of Management Journal. 1991;34(4):827-847. 
Coyne JC, Anderson KK. Marital status, marital satisfaction, and support processes among women at high risk for breast cancer. Journal of Family Psychology. 1999;13(4):629-641.

Crowne, Kerri Anne. What Leads to Cultural Intelligence? Widener University, Chester, PA. Kelley School of Business, 54, 391-399, 2008.

Davidov E, Schmidt P, Schwartz SH. Bringing values back in: The adequacy of the European Social Survey to measure values in 20 countries. Public Opinion Quarterly, 72, 420-445, 2008.

DaVinci L. Thoughts on Art and Life. Tranlated by Maurice Baring. Boston: The Merrymount Press, 1906. Also available at http://www.gutenberg.org/files/29904/29904-h/29904-h.htm.

Deci EL, Ryan, RM. Intrinsic motivation and self-determination in human behaviour. New York: (NY): Plenum, 1985.

Department of Defense. Functions of the Department of Defense and Its Major Components Department of Defense Directive Number 5100.01, 24 December 2010.

DeRue S, Morgeson F. Developing a taxonomy of team leadership behavior in self-managing teams. 20th Annual Conference of the Society for Industrial and Organizational Psychology, April. Los Angeles, (CA): 2005.

Deutsch, M. Educating for a peaceful world. American Psychologist. 1993;48,510-517.

Donohew L, Zimmerman R, Cupp PS, Novak S, Colon S, Abell, R. Sensation Seeking, impulsive decision making, and risky sex: implications for risk-taking and design of interventions. Personality and Individual Differences, 28, 1079-1091, 2000.

Dror I, Busemeyer J, Basola B. Decision making under time pressure: An independent test of sequential sampling models. Memory \& Cognition. 1999;27(4):713-725.

Dyreng S, Mayew W, Williams C. Religious social norms and corporate financial reporting. Journal of Business, Firnace and Accounting. 2012;39(7-8):845-875.

Fatkin LT, Patton DJ. Mitigating the effects of stress through cognitive readiness. In: Performance Under Stress, Hancock \& Szalma, editors 2008.

Feinstein JS. The relationship between socioeconomic status and health: A review of literature. The Milbank Quarterly 1993;71(2): 279-322.

Finucane M, Slovic P, Mertz C, Slynne J, Satterfield T. Gender, race, and perceived risk: The "white male” effect. Health, Risk \& Society. 2000;159-172.

Fischer J, Fischer P, Englich B, Aydin N, Frey D. Empower my decisions: The effects of power gestures on confirmatory information processing. Journal of Experimental Social Psychology. 2011;47,1146-1154. 
FM 6-22. US Department of Army. Army leadership: Competent, confident and agile. Washington, DC, Author, 2006.

Forgas JP. On bad mood and peculiar people: Affect and person typicality in impression formation. Journal of Personality and Social Psychology. 1992;62,863-875.

Forgas JP. Sad and guilty? Affective influences on the explanation of conflict episodes. Journal of Personality and Social Psychology. 1994;66,56-68.

Forgas, JP. Feeling and thinking: The influence of affect on social cognition and behaviour. Foreign psychology. 2001;14, 60-82.

Gal R, Jones FD. A Psychological Model of Combat Stress. In Jones FD, Sparacino LR, Wilcox VL, Rothberg JM, Stokes JW, editors. War psychiatry. Washington, DC: Office of Surgeon General, Walter Reed Army Institute of Research; 1995. pp. 133-148.

Gal R, Jones FD. A Psychological Model of Combat Stress. Washington, DC: Office of the Surgeon General, US Army, 1999.

Galinsky A, Magee J, Inesi M, Gruenfeld, D. Power and perspectives not taken. Psychological Science. 2006;17(12):1068-1074.

Galinsky AD, Moskowitz GB. Perspective taking: decreasing stereotype expression, stereotype accessibility, and in-group favoritism. Journal of Personality and Social Psychology. 2000; 78(4):708-724.

Gehlbach H. Social perspective taking: A facilitating aptitude for conflict resolution, historical empathy, and social studies achievement. Theory and Research in Social Education. 2004; 32(1): 39-55.

Glazer R, Steckel J, Winer R. Locally rational decision making: The distracting effect of information on managerial performance. Management Science. 1992;38(2): 212-226.

Goebel D. Military-Media Relations: The future media environment and its influence on military operations. Air War College, Department of the Air Force. Maxwell Air Force Base, AL, 1995.

Golec de Zavala A, Cichocka A, Eidelson R, Nuwan J. Collective narcissism and its social consequences. Portland, USA: Paper presented at Annual Meeting of International Society of Political Psychology, 2007.

Gordon MM. Assimilation in American Life. New York, (NY): Oxford University Press, 1964, p. 27.

Greco V, Roger D. Uncertainty, stress , and health. Personality and individual differences, 34, 1057-1068. 
Guss C. Decision making in individualistic and collectivistic cultures. Online Readings in Psychology and Culture. 2004:4(3). Downloaded 1/3/2012.

Hannaman DL. Methods to improve cultural communication skills in special operations forces. Unpublished HumRRO report, 1997.

Headquarters, Department of the Army. Army doctrine reference publication (ADRP) 3-0 Unified Land Operations. Washington (DC): 16 May 2012.

Hegarty WH, Sims HP. Organizational philosophy, policies, and objectives related to unethical decision behavior: A laboratory experiment. Journal of Applied Psychology. 1979;64(3): 331.

Herring, RD. Developing biracial ethnic identity: A review of the increasing dilemma. Journal of Multicultural Counseling and Development. 1995; 95(23): 29-38.

Hilary G, Hui KW. Does religion matter in corporate decision making in America? Journal of Financial Economics. 2009;93(3):455-473.

Hoop JG, DiPasquale T, Hernandez JM, Roberts, LW. Ethics and culture in mental health care. Ethics \& Behavior. 2008;18(4):353-372.

Hsee CK, Weber EU. Cross national difference in risk preference and lay predictions. Journal of Behavioral Decision Making 12. 1999:165-179. Print.

Huffman W. Decision making: The role of education. American Journal of Agricultural Economics. 1974;56(1):85-97.

Jackson S, May K, Whitney K. Understanding the dynamics of diversity in decision-making teams. In: Guzzo RA, Salas E. and Associates editors. Team Effectiveness and Decision Making in Organizations, (pp. 204-260), San Francisco (CA): Jossey-Bass; 1995. Pp 204260.

Jehn K, Chadwick C, Thatcher S. To agree or not to agree: the effects of value congruence, individual demographic dissimilarity, and conflict on workgroup outcomes. International Journal of Conflict Management. 1997; 8(4):287-305.

Jessup L, Tansik D. Decision making in an automated environment: The effects of anonymity and proximity with a group decision support system. Decision Sciences. 22(2), 266-279, 1991.

Johnson, David W. Cooperativeness and social perspective taking. Journal of Personality and Social Psychology. Feb 1975; 31(2): 241-244.

Joint and Coalition Operational Analysis (JCOA). Decade of war, volume 1: enduring lessons from the past decade of operations. Suffolk, VA, 2012. 
Joint Chiefs of Staff. Mission Command White Paper. 3 April 2012.

Kerstholt J. The effect of time pressure on decision-making behavior in a dynamic task environment. Acta Psychologica. 1994;86-1,89-104.

Kim S, Hasher L. The attraction effect in decision making: superior performance by older adults. Quarterly Journal of Experimental Psychology: Human Experimental Psychology. 2005;58A(1):120-133.

Kirkland FR. Honor, combat ethics, and military culture. Military medical ethics. Volume 1. 2003:157-197. Web. 15 Mar 2010. http://www.bordeninstitute.army.mil/published.html.

Kobus D, Proctor S, Bank T. Decision Making in a Dynamic Environment: The effects of experience and information uncertainty. San Diego: SPAWAR Systems Center, 2000.

Kwak J, Haley W. Current research findings on end-of-life decision making among racially or ethnically diverse groups. The Gerontologist. 2005;45(5):634-641.

Lamm C, Batson CD, Decety J. The neural substrate of human empathy: effects of perspectivetaking and cognitive appraisal. Journal of Cognitive Neuroscience. 2007;19 (1):42-58.

Langerholc B. Cohesion in Multinational Military Units. US Army Command and General Staff College, Master of Military Art and Science. Fort Leavenworth, KS, 2010.

Lazarus RS, Folkman S. Stress, appraisal, and coping. New York (NY): Springer, 1984.

Leiber MJ, Jamieson KM. Race and decision making within juvenile justice: The importance of context. Journal of Quantitative Criminology. 1995;11(4):363-384.

Levinson W, Kao A, Kuby A, Thisted R. Not all patients want to participate in decision making, A national study of public preferences. Journal of General Internal Medicine. (2005);20(6):531-535.

Livingston S. Clarifying the CNN effect: An examination of the media effects according to type of military intervention. Research paper R-18. The Joan Shorenstein center for public policy, Harvard University, 1997.

Loe TW, Ferrell L, Mansfield P. A review of empirical studies assessing ethical decision making in business. Journal of Business Ethics. 2000; 25(3):185-204.

Martin LB, Bandali F, Lamoureux T. Survey of literature pertaining to decision-making styles and individual factors (DRDC Toronto No. CR 2005-281. Toronto, Ontario, CA:

Department of National Defence, 2005. 
Mayer JD. A classification of DSM-IV-TR mental disorders according to their relation to the personality system. In JC Thomas \& DL, Segal, editors. Comprehensive handbook of personality and psychopathology (CHOPP) Vol. 1: Personality and everyday functioning. New York (NY): John Wiley \& Sons, 2005.

McKinley E, Garrett J, Evans A, Danis M. Differences in end-of-life decision making among black and white ambulatory cancer patients. Journal of General Internal Medicine. 1996; 11(11):651-656.

McLaughlin LA, Braun KL. Asian and pacific islander cultural values: considerations for health care decision making. Health \& Social Work. 1998;23(2):116-126.

Morrison J, Fletcher J. Cognitive Readiness. Institute for Defense Analyses, 2002.

Munene JC, Schwartz SH, Smith PB. Development in sub-Saharan Africa: cultural influences and managers' decision behavior. Public Administration \& Development. 2000;20(4):339_ 351.

Nash R, Hudson A, Cilia L. Mapping Political Context: A Toolkit for Civil Society Organizations. Overseas Development Institute. United Kingdom, Jul 2006.

Norenzayan A, Nisbett RE. Culture and causal cognition. Current Directions in Psychological Science. 2000;9,132-135.

North Carolina center for world languages \& cultures (NCCWLC). Culture communication skills template (working draft), 1996.

O’Boyle JG. The culture of decision making. R\&D Innovator Volume 5, Number 12. [accessed 1996 at] http://www.winstonbrill.com/bril001/html/article_index/articles/251300/article251_body.html on 3 Jan 2013.

Olsen-Fulero L, Fulero SM. Commonsense rape judgments: An empathy-complexity theory of rape juror story making. Psychology, Public Policy, and Law. 1997;3(2-3):402-427.

Oudeyer P-Y, Kaplan F. How can we define intrinsic motivation? Proceedings of the 8th International Conference on Epigenetic Robotics: Modeling Cognitive Development in Robotic Systems (Epirob 2008), Lund University Cognitive Studies, Lund: LUCS, Brighton.

Parasuraman R, Riley V. Humans and automation: Use, misuse, disuse, abuse. Human Factors. 1997;39, 230-253.

Passalacqua, R. Effects of media information on cancer patients' opinions, feelings, decisionmaking process and physician-patient communication. Cancer. 2004;100(5): 1077-1084.

Patton DJ, Fatkin LT, Breitenbach JS. (In Review). Identifying personal, situational, and organizational factors related to student performance and retention. Aberdeen Proving Ground, MD: US Army Research Laboratory. 
Payson, KE. Check One Box: Reconsidering Directive No. 15 and the Classification of MixedRace People. 84 California Law Review. 1996;84(4).

Perkins AM, Cooper A, Abdellal M, Smillie L, Corr PJ. Personality and defensive reactions: Fear, trait anxiety, and threat magnification. Journal of Personality. 2010;78(3):1071-1090.

Phillips JM, Gully SM. Role of goal orientation, ability, need for achievement, and locus of control in the self-efficacy and goal-setting process. Journal of Applied Psychology. 1997; 82(5):792-802.

Pinkleton B, Austin E. Individual motivations, perceived media importance, and political disaffection. Political Communication. 2001;18(3):321-334.

Pinkleton BE, Austin EW. Exploring relationships among media use frequency, perceived media importance, and media satisfaction in political disaffection and efficacy. Mass communication and society, 5, 144-166, 2002.

Pirnie B, Simons W. Soldiers for peace: critical operational issues. National Defense Research Institute, RAND. Santa Monica, CA, 1996.

Poltrock S, Handel M, Boywer H, Waggett P, Gentle E. Modeling simulated military mission context. Annual Conference of ITA, 2009.

Reeder GD, Trafimow D. Attributing motives to other people. In: BF Malle SD, Hodges editors. Other minds: How humans bridge the divide between self and others. New York: The Guilford Press, 2005.

Riggle EDB, Johnson MMS. Age difference in political decision making: strategies for evaluating political candidates. Political Behavior. 1996;18(1): 99-118.

Roan L, Strong B, Foss P, Yager M, Gehlbach H, Metcalf KA. Social Perspective taking. Technical Report 2009-1259. US Army Research Institute for the Behavioral and Social Sciences; Arlington, VA, 2009.

Robertson C, Fadil PA. Ethical decision making in multinational organizations: A culture-based model. Journal of Business Ethics. May 1999;19(4):385.

Robertson DC, Schlegelmilch BB. 1983. Corporate institutionalization of ethics in the United States and Great Britain. Journal of Business Ethics. 1993;12(4): 301-312.

Ros M, Schwartz SH, Surkiss, S. Basic individual values, work values, and the meaning of work. Applied Psychology: An International Review. 1999;48(1): 49-71.

Ross KG. Toward an operational definition of cross-cultural competence from interview data. defense equal opportunity management institute directorate of research, 2008. 
Rotter JB. Generalized expectancies for internal versus external control of reinforcement. Psychological Monographs. 1966; 80,1-28.

Rotter JB. Locus of control. [accessed 2012 Sep 21]. http://www.inlightimes.com/ archives/2006/12/locus-control.htm.

Samms C, Animashaun A, Henry S, Hill S, Patton D, Ungvarsky, D. Towards a taxonomy of socio-cultural factors that influence decision making. Proceedings of the 2nd international conference on cross-cultural decision making of the 4th international conference on applied human factors and ergonomics, San Francisco, CA, Jul 2012.

Sanbonmatsu DM, Fazio RH. The role of attitudes in memory-based decision making. Journal of Personality and Social Psychology. 1990;59(4):614-622.

Scherpereel, C. Decision orders: a decision taxonomy. Management Decision. 2006;44(1):123126.

Schwartz SH. A theory of cultural value orientations: Explication and applications. In: Esmer Y, Pettersson ,T. Measuring and mapping cultures: 25 years of comparative value surveys. 2007 p. 33-78, Leiden, Boston: Brill.

Schwartz SH. A Theory of cultural values and some implications for work. Applied Psychology: An International Review. 1999;48(1):23-47.

Schwartz SH. Universals in the content and structure of values: theoretical advances and empirical tests in 20 countries. Advances in Experimental Social Psychology. 1992; 25,1-65.

Schwarzer R. (1997). John D, Catherine T. MacArthur Research Network on Socioeconomic Status and Health: Anxiety. [accessed 2014 Jun 3] from http://web.archive.org/web/ 20070920115547/http:/www.macses.ucsf.edu/Research/Psychosocial/notebook/anxiety.html.

Segal MW. Gender and the military. handbook of the sociology of gender. New York, (NY): 1999.

Shulman K, Berlin JA, Harless W, Kerner JF, Sistrunk S, Gersh BJ, Dube R, Taleghani CK, Burke JE, Williams S, Eisenberg J, Ayers W, Escarce JJ. The effect of race and sex on physicians' recommendations for cardiac catheterization. New England Journal of Medicine. 1999;340(8):618-26.

Silliman RA, Troyan SL, Guadagnoli E, Kaplan SH, Greenfield S. The impact of age, marital status, and physician-patient interactions on the care of older women with breast carcinoma. Cancer. 1997;80(7):1326-1334.

Srnka KJ. Culture’s role in marketers’ ethical decision making: An integrated theoretical framework. academy of marketing science review volume 2004 no. 01 [accessed at 2004]. http://www.amsreview.org/articles/srnka01-2004.pdf. 
Stanton NA. An introduction to trust in military teams. School of Civil Engineering and the Environment, University of Southampton. Southampton, UK, 2011.

Tannert C, Elvers HD, Jandrig B. The ethics of uncertainty. In the light of possible dangers, research becomes a moral duty. EMBO Rep. 8(10): 892-6, 2007.

Tatham P, Spens K. Towards a humanitarian logistics knowledge management system. Disaster prevention and management. 20(1): pp. 6-26, 2011.

Titchener E. A textbook of psychology. New York (NY): Macmillan; 1924.

University of Kentucky. University of Kentucky student activities, leadership, and involvement: group dynamics. [accessed 2012 Oct 19] from University of Kentucky student activities leadership: www.uky.edu/GetInvolved/Leadership/pdf/Group\%20Dynamics.pdf.

US Nuclear Regulatory Commission. Fitness-for-Duty Programs. [accessed 2012 Sep 2] from: http://www.nrc.gov/reactors/operating/ops-experience/fitness-for-duty.html).

Vitaliano PP, Maiuro RD, Russo J, Becker J. Raw versus relative scores in the assessment of coping strategies. Journal of Behavioral Medicine. 1987;10,1-18.

Vitell SJ, Nwachukwu SL, Barnes JH. The effects of culture on ethical decision making: an application of hofstede's typology. Journal of Business Ethics. 1993;12,753-760.

Vrendenburgh AG, Cohen HH. Does culture affect risk perception? Proceedings of the Human Factors and Ergonomics Society 39th Annual Meeting. San Diego, (CA): 1995. 1015-1019. Print.

Warren HC, Carmichael L. Elements of human psychology (Rev. Ed.: Boston, MA: Houghton Mifflin, 1930), p. 333/cited in Allport, Pattern \& growth in personality (1937/1961), p. 36.

Webster, C. Attitudes toward marketing practices: The effects of ethic identification. The Journal of Applied Business Research. 1990-91;7(2):107-116.

Whittaker M, Breininger K. Taxonomy Development for Knowledge Management. World Library and Information Congress: 74th International Federation of Library Associations and Institutions (IFLA) General Conference and Council, 10-14 August 2008, Quebec, Canada.

Willems S, De Maesschalck S, Deveugele M, Derese A, De Maeseneer J. Socio-economic status of the patient and doctor-patient communication: does it make a difference? Patient education and counseling 56, 139-146, 2005.

Wunderie W. Through the lens of culture awareness: planning requirements in wielding the instruments of national power. RAND Corporation. 2007.

Yaniv I. Receiving other people’s advice: Influence and benefit. Organizational behavior and human decision processes. 93, pp 1-13 2004. 
Yellen S, Cella D. Someone to live for: social well-being, parenthood status, and decision making in oncology. Journal of Clinical Oncology. 1995;13(5): 1255-1264.

Zuckerman M. Sensation seeking scale IV. Journal of Consulting and Clinical Psychology. 1971;36(2):45-52. 
INTENTIONALLY LEFT BLANK. 
Appendix. First Cut at Taxonomy 


\section{Initial Taxonomy Development:}

The group addressed the following areas before beginning to brainstorm to focus the brainstorming session: purpose of the taxonomy, potential users of the taxonomy, and the scope of the taxonomy. The researchers also listed assumptions regarding the taxonomy that were made during the brainstorming process.

\section{Purpose}

- Development of models (qualitative/cognitive)

- Development of interface design principles

- Bin past research into categories to identify gaps

- Identify skills to train

- What to model in host population

- Identify areas where expertise is needed

\section{Potential users}

- Army Research Laboratory Human Research and Engineering Directorate (ARL HRED)

- $\quad$ US Army Research Institute (ARI)

- Engineer Research and Development Center (ERDC)

- Military force designers

- Military trainers

- Other DOD services

- Academia conducting military research

\section{Scope}

The scope of the taxonomy is intended to be directed at social-cultural factors that impact individual Soldier decision making. The topic of Soldier communication is also of interest and the draft taxonomy might have future application to that topic. The focus is on the decision making of US Soldiers, Commanders, and small unit leaders. We are addressing decision making within the operational or mission environment. When considering the socialcultural factors, we will be addressing those factors within a specific region or environment for each analysis. There was no intention of examining cultural factors that are the same across all cultures — only regions or people with an identifiable social and cultural factors will be examined at a single time. 


\section{Assumptions}

We identified several assumptions in developing the taxonomy.

- Context will change

- $\quad$ Factor $=$ something that can be measured or identified

- $\quad$ Demographic $=$ standard answer/multiple choice

- $\quad$ Personality factor $=$ state versus trait

- Decision making in operational context

- Subculture influences

\section{Presentation of Initial Taxonomy $5+2$}

The initial taxonomy is composed of 7 primary topic areas. The first 4 (Demographics, Personality, Experience, Values) each address individual characteristics. The fifth category, Context, addresses the dynamic operational environment in which the Soldier must make decisions. It should be noted that many of the individual characteristics are more static than dynamic. While we do not mean to assume that individual characteristics cannot change, we do recognize that many of these characteristics develop over time and, therefore, are not as dynamic as the mission environment in which the Soldier operates. The sixth category is composed of factors that are external to the individual Soldier but which may still impact individual decision making. Finally, the last category includes possible outcomes and results of combinations of the individual characteristics.

The 7 categories and subcategories are listed in Table A-1. Items in bold were included in the final taxonomy. 
Table A-1 Initial taxonomy

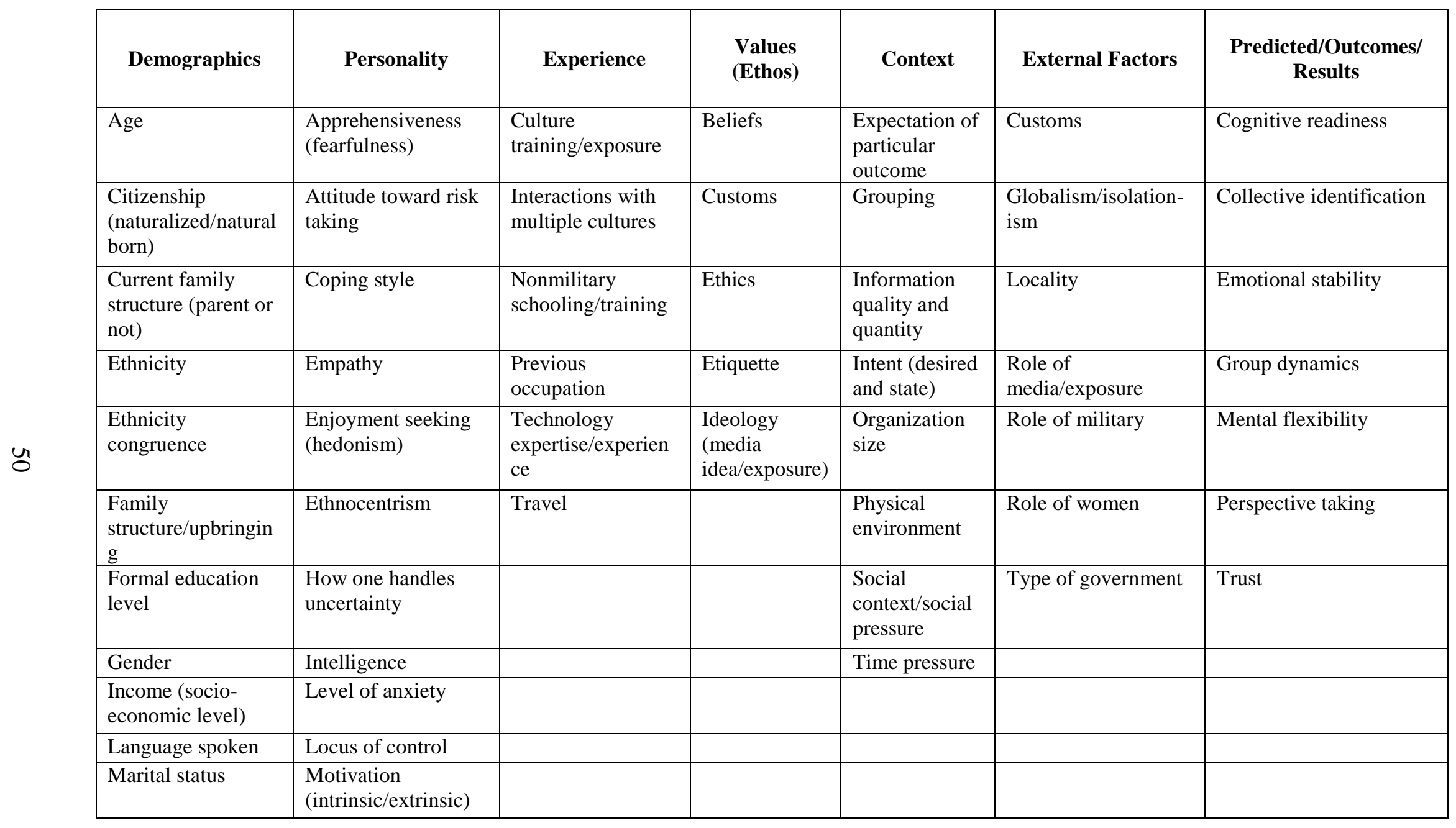


Table A-1 Initial taxonomy (continued)

\begin{tabular}{|c|c|c|c|c|c|c|}
\hline Demographics & Personality & Experience & $\begin{array}{l}\text { Values } \\
\text { (Ethos) }\end{array}$ & Context & External Factors & $\begin{array}{c}\text { Predicted/Outcomes/ } \\
\text { Results }\end{array}$ \\
\hline $\begin{array}{c}\text { Military } \\
\text { demographics } \\
\text {-Rank } \\
\text {-Military status } \\
\text { subgroups -(reserve } \\
\text { vs. active) } \\
\text {-Position (MOS) } \\
\text { combat vs. } \\
\text { organization } \\
\text {-Military } \\
\text { training/schooling } \\
\text {-Tenure in military } \\
\text { (time in service) } \\
\text {-Role }\end{array}$ & $\begin{array}{c}\text { Need for } \\
\text { achievement }\end{array}$ & & & & & \\
\hline Nationality & Risk perception & & & & & \\
\hline $\begin{array}{l}\text { Physical attributes } \\
\text { (height, weight, } \\
\text { hair color, skin } \\
\text { color, stamina, } \\
\text { strength) }\end{array}$ & Self-efficacy & & & & & \\
\hline \multicolumn{7}{|l|}{ Political affiliation } \\
\hline \multicolumn{7}{|l|}{ Race } \\
\hline \multicolumn{7}{|l|}{$\begin{array}{c}\text { Religion } \\
\text { (type/degree) }\end{array}$} \\
\hline $\begin{array}{l}\text { Rural vs. suburban } \\
\text { vs. urban }\end{array}$ & & & & & & \\
\hline
\end{tabular}


INTENTIONALLY LEFT BLANK. 


\section{List of Symbols, Abbreviations, and Acronyms}

\begin{tabular}{ll} 
ARI & US Army Research Institute \\
ARL & US Army Research Laboratory \\
COIN & counterinsurgency \\
CRM & customer relationship management \\
DOD & Department of Defense \\
ERDC & Engineer Research and Development Center \\
HRED & Human Research and Engineering Directorate \\
HSCB & Human Social, Culture and Behavior \\
HumRRO & Human Resources Research Organization \\
JCOA & Joint and Coalition Operational Analysis \\
MiTT & military transition team \\
MOS & Military Occupational Specialty \\
NCCWLC & North Carolina Center for World Languages \& Cultures \\
PME & professional military education \\
RISC-D & Relevant Information for Social Cultural Depiction \\
SPT & Social Perspective Taking \\
TCC & TRADOC Culture Center \\
TRADOC & US Army Training and Doctrine Command \\
\hline
\end{tabular}




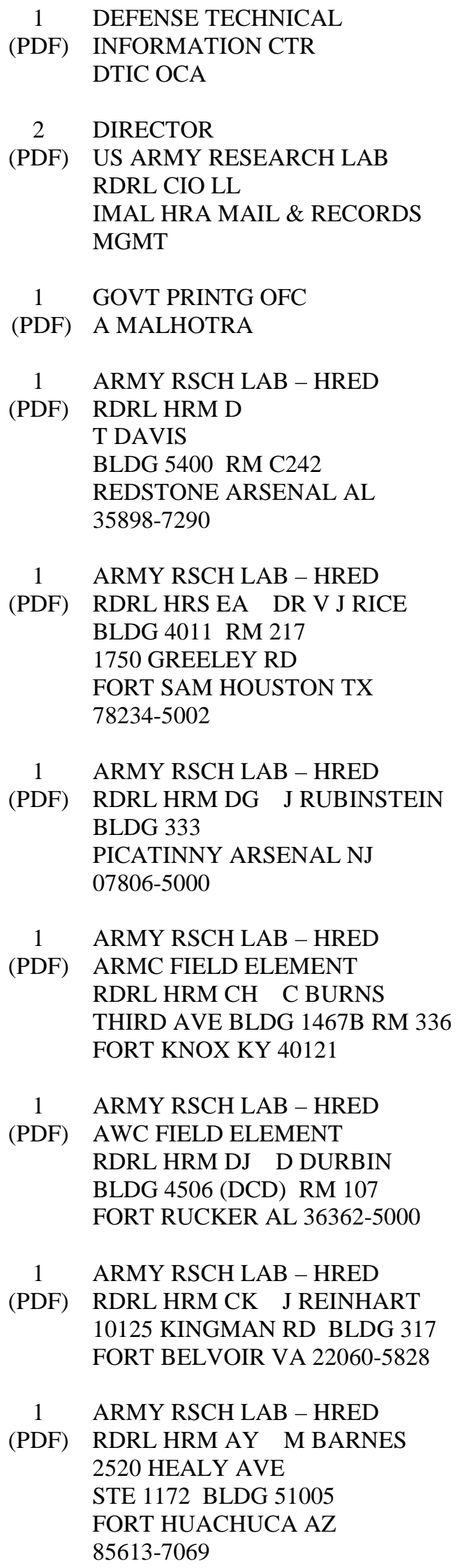

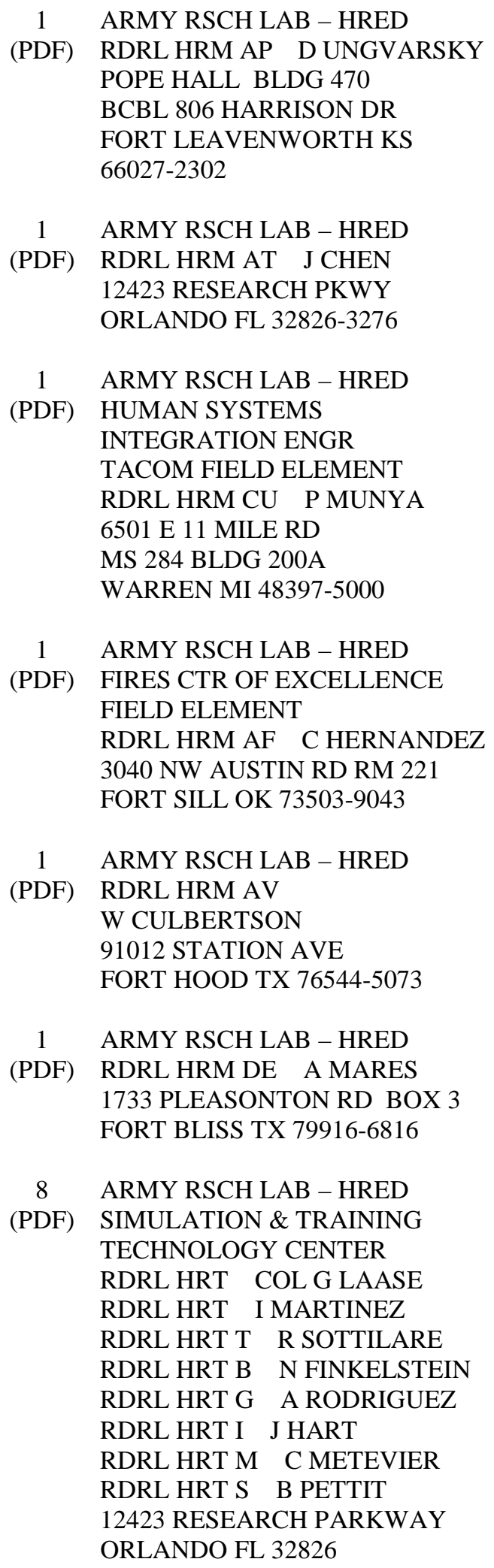




$\begin{array}{cl}11 & \text { ARMY RSCH LAB - HRED } \\ \text { (PDF) } & \text { HQ USASOC } \\ & \text { RDRL HRM CN R SPENCER } \\ & \text { BLDG E2929 DESERT STORM DR } \\ & \text { FORT BRAGG NC 28310 } \\ 1 & \\ \text { ARMY G1 } \\ \text { (PDF) } & \text { DAPE MR B KNAPP } \\ & \text { 300 ARMY PENTAGON RM 2C489 } \\ & \text { WASHINGTON DC 20310-0300 } \\ & \\ \text { ABERDEEN PROVING GROUND } \\ \text { 12 } \\ \text { DIR USARL } \\ \text { RDRL HR } \\ \text { L ALLENDER } \\ \text { P FRANASZCZUK } \\ \text { C SAMMS } \\ \text { RDRL HRM } \\ \text { P SAVAGE-KNEPSHIELD } \\ \text { RDRL HRM AL } \\ \text { C PAULILLO } \\ \text { RDRL HRM B } \\ \text { J GRYNOVICKI } \\ \text { RDRL HRM C } \\ \text { L GARRETT } \\ \text { RDRL HRS } \\ \text { J LOCKETT } \\ \text { RDRL HRS B } \\ \text { M LAFIANDRA } \\ \text { RDRL HRS C } \\ \text { K MCDOWELL } \\ \text { RDRL HRS D } \\ \text { A SCHARINE } \\ \text { RDRL HRS E } \\ \text { D HEADLEY } \\ \end{array}$


INTENTIONALLY LEFT BLANK. 